\title{
Le goût des acides aminés, des peptides et des protéines : exemple de peptides sapides dans les hydrolysats de caséines
}

\author{
F Roudot-Algaron \\ Unité de recherche de biochimie et structure des protéines, \\ Inra, 78352 Jouy-en-Josas cedex, France
}

(Reçu le 18 avril 1995 ; accepté le 9 novembre 1995)

\begin{abstract}
Résumé - Après quelques définitions et un bref rappel sur la physiologie du goût, cette revue s'attache à décrire les connaissances actuelles sur le goût des acides aminés et des peptides. En s'appuyant sur la théorie des cinq goûts (amer, sucré, salé, acide, umami), nous avons tenté de décrire dans chaque cas la relation structure-goût. Nous avons regroupé, sous forme de tableaux, les peptides développant une saveur en solution, ainsi que leurs seuils de détection. Le cas des hydrolysats de caséines est développé plus particulièrement. II y apparaît une forte proportion de peptides amers. Les autres saveurs y sont mal représentées, bien que présentes dans d'autres hydrolysats de protéines.
\end{abstract}

protéine / caséine / protéolyse / hydrolyse / goût

Summary - The taste of amino acids, peptides and proteins : examples of tasty peptides in casein hydrolysates. After the presentation of some definitions and a brief overview on taste physiology, this review describes the actual knowledge on the taste of amino acids and peptides. According to the five tastes theory, we discuss for each case the taste-structure relation. Tasty peptides are presented in tables with their taste thresholds. Savory-peptides in casein hydrolysates are listed, especially bitter peptides. The other tastes are not important in casein hydrolysates but some of them can take place in other protein hydrolysates.

protein / casein / proteolysis / hydrolysis / taste 


\section{INTRODUCTION}

Un aliment, quel qu'il soit, doit avoir des qualités nutritionnelles et être agréable à ingérer. Pour cela, la flaveur est un élément important : elle englobe les notions de goût et d'olfaction.

Le goût est défini par la perception d'un composé chimique mis en contact avec les bourgeons gustatifs de la langue. Souvent, le terme goût est improprement utilisé pour décrire l'arôme, c'est-à-dire la sensation due aux molécules rendues volatiles en bouche et ayant atteint l'épithélium olfactif par la voie rétro-nasale. Ainsi, lorsqu'un aliment est consommé, les deux types de stimuli sont confondus et l'impression rendue s'appelle la flaveur. Toutefois, la frontière goût-flaveur n'est pas très bien définie (Birch, 1983). En effet, la flaveur, qui fait intervenir les récepteurs olfactifs, contribue également aux réponses gustatives (Hettinger et al, 1990). Dans des conditions ordinaires de dégustation, il est donc difficile de percevoir le goût sans l'intervention des molécules aromatiques, mais il est tout à fait normal de sentir des odeurs, directement par le nez et sans l'intervention d'autres stimuli (Shepherd, 1988).

Outre le goût et l'olfaction, les qualités sensorielles d'un aliment peuvent être complétées par une description visuelle (couleur, aspect), auditive (bruit perçu lors de la mastication) et somesthésique (sensibilité tactile, kinesthésique, thermique...) (McLeod, 1990).

Le goût est un concept très ancien. Aristote, par exemple, décrivait le doux, l'amer, l'onctueux, le salé, l'aigre, l'âpre, l'astringent et l'acide. Au XVIII ${ }^{e}$ siècle, Linné discernait différentes qualités gustatives incluant des sensations olfactives ou mécaniques : l'humide, le sec, l'acide, l'amer, le gras, l'astringent, le sucré, le muqueux. II a fallu attendre 1824 pour que Chevreul fasse la différence entre " le tact de la langue, le goût et l'odorat ", après avoir lui-même testé, narines pressées ou libres, la glace, les métaux, le chocolat ou la menthe (Jamma, 1989). A peine la physiologie du goût est-elle née que le concept des quatre saveurs s'installe ; il consiste à dire que toute saveur peut être décrite par l'un des caractères suivants : sucré, salé, acide, amer. Toutefois, l'existence d'un cinquième goût, la saveur " umami " vient remettre en doute cette théorie des quatre saveurs dès 1908. Le goût umami, qui signifie délicieux en Japonais, est comparable à un goût de bouillon et est représenté par le goût du glutamate de sodium. En 1916, l'allemand Henning (cité par Jamma, 1989), pour qui il existe un continuum de goût entre ces quatre références, met également en doute cette théorie. La question reste d'actualité : ces cinq goûts sont-ils suffisants pour décrire un aliment? Des expériences ont, en effet, montré que la saveur sucrée des différents édulcorants utilisés de nos jours n'est pas ressentie de la même façon (Teeuwen, 1991). De plus, de nombreuses molécules (D-Leu, quinine, acide glycyrrhizique) ont des goûts originaux difficiles à décrire à l'aide des goûts de base (anonyme, 1990).

La difficulté à résoudre cette question provient, en partie, de notre système de détection. Le goût est ressenti essentiellement sur la face supérieure de la langue. Un demi million de récepteurs gustatifs sont regroupés en formations appelées bourgeons du goût et situées à l'intérieur des papilles gustatives. Les bourgeons du goût sont répartis pour moitié dans les papilles fongiformes et les papilles caliciformes (fig 1). Les papilles filiformes servent à retenir la salive. Les molécules sapides déclenchent une sensation gustative au contact des récepteurs situés à la surface des cellules sensorielles. Ce mécanisme est à l'origine d'un influx nerveux conduit au cerveau par des fibres nerveuses (nerf vague, glosso-pharyngien, et corde du tympan). Certaines de ces fibres ne codent pas les seules sensations gustatives mais peuvent également transmettre, 


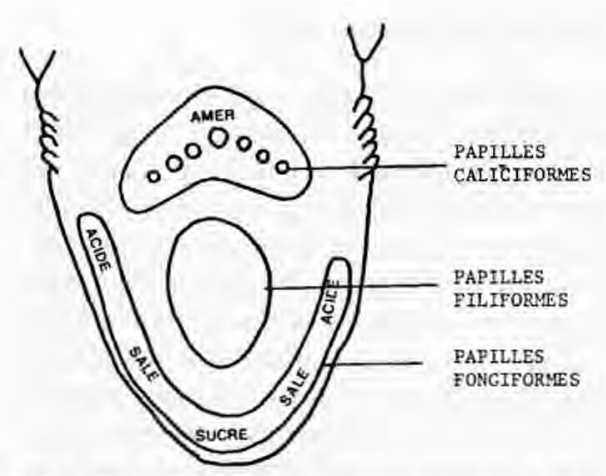

Fig 1. Répartition des papilles gustatives et des quatre goûts de base sur le dos de la langue. Distribution of taste buds on the tongue and localization of the four basic tastes.

par exemple, les sensations thermiques. Les cellules n'ont pas une spécificité très grande, ainsi une même cellule peut répondre à différents stimuli avec des intensités différentes. Toutefois, en ce qui concerne les quatre goûts de base, on peut définir des zones plus ou moins sensibles. Comme indiqué sur la figure 1 , le goût sucré est le plus facilement détecté en bout de langue, le salé est ressenti en bout mais vers les côtés, l'acidité sur les côtés, et enfin, l'amertume à l'arrière de la langue. Les papilles sensibles au goût amer sont assez profondes, aussi, la sensation met du temps à être perçue mais elle est plus persistante.

La plupart des travaux menés sur le goût font référence à la théorie des quatre saveurs et l'on trouve de plus en plus souvent le terme " umami " dans la bibliographie. Nous nous intéresserons donc principalement à ces cinq saveurs dans la suite de cette revue. Nous nous efforcerons de décrire la relation goût-structure et de discuter de l'impact des protéines et de leurs produits de dégradation sur la saveur des aliments et tout particulièrement, nous développerons le cas des hydrolysats de caséines et des fromages.

\section{LE GOÛT DES ACIDES AMINÉS}

La contribution des acides aminés au goût des aliments a été mise en évidence pour la première fois en 1909 par Ikeda à l'université de Tokyo. En effet, il a montré que le glutamate de sodium (MSG) était l'un des composants essentiels du goût des aliments traditionnels japonais (Ikeda, 1909). Ainsi, le goût du saké, du miso, de la sauce de soja était présumé provenir des acides aminés libérés par les protéines lors de la fermentation. Beaucoup plus tard, en Europe et aux États-Unis, le goût du fromage a été attribué aux acides aminés libérés pendant l'affinage.

Langler et al, en 1967, reconstituent une flaveur de fromage suisse en combinant certains acides aminés (L-Pro, Gly, Ser, Thr, Asp, Glu, Cys, Trp, His, Lys) avec des acides gras et des composés volatils. Solms (1969) reconstitue, à partir d'acides aminés et de nucléotides, la saveur de base de la pomme de terre. Depuis, de nombreux travaux ont porté sur le goût des acides aminés et sur leur impact dans la flaveur des aliments. Ainsi, il a été montré que certains acides aminés sont essentiels dans le goût de divers aliments et certains sont même utilisés comme additifs pour intensifier la flaveur (Kleeman et al, 1985). La méthionine, par exemple, est le composé le plus important dans le goût de l'oursin et joue un rôle essentiel dans l'arôme des pommes de terre frites. La glycine qui contribue de façon importante au goût sucré du crabe et du homard (Nishimura et Kato, 1988) est également abondante dans les moules et les crevettes et utilisée pour en intensifier l'arôme. La flaveur de la croûte de pain est liée à la présence de proline. Phénylalanine, leucine et valine interviennent dans la saveur du chocolat. L'arôme de l'oignon est rehaussé par addition de cystéine. Dans un extrait de viande, aucun acide aminé n'est essentiel mais une combinaison des acides aminés produit une sensation très com- 
plexe (Kirimura etal, 1969). D'après Kleeman et al (1985), la cystéine semble toutefois en être un élément important.

Pour mieux comprendre le rôle des acides aminés dans les aliments, de nombreux travaux ont porté sur leur saveur. Solms et al (1965) ont montré qu'à une faible concentration $\left(0,3 \%\right.$ dans $\mathrm{H}_{2} \mathrm{O}$, $\mathrm{pH}=6$ ), un jury décrit le goût des acides aminés (énantiomères $D$ et $L$ ). En solution aqueuse, Meister (1965) et Birch et Kemp (1989) les ont également caractérisés. On a trouvé le même type de résultats à partir de cristaux déposés sur la langue (Schiffman et Dackis, 1975 ; Schiffman et Engelhard, 1976 ; Haefeli et Glaser, 1990). Les seuils de reconnaissance ont été estimés par Wieser et Belitz (1975), Wieser et al (1977), Schiffman et al (1981) et Haefeli et Glaser (1990).

Le tableau I (Schiffman et Engelhard, 1976) montre les résultats obtenus par sept équipes différentes en ce qui concerne la saveur. Une comparaison des seuils obtenus a été présentée par Haefeli et Glaser (1990). Ces données permettent d'apprécier la complexité des analyses organoleptiques. En effet, notre système gustatif étant différent d'une personne à l'autre, il existe, naturellement, des différences interindividuelles (Yokomukai et al, 1993). De plus, en fonction de son âge (Stevens et Cain, 1993), de son histoire ou de son apprentissage, un jury ne donne pas toujours la même réponse pour une molécule identique.

Une étude récente (Laing et al, 1993) a montré que les différences de jugement observées entre des sujets de cultures différentes (Australiens et Japonais) provenaient plus de leur propre expérience que d'influences typiquement génétiques. De plus, la préparation de l'échantillon et les conditions de dégustation peuvent apporter des différences. Toutefois, malgré les difficultés à estimer une saveur, il a été possible de classer les acides aminés en fonction de leur propriétés organoleptiques.

\section{Les acides aminés amers}

D'après Solms (1969), seuls quatre acides aminés sont amers : L-Trp, L-Phe, L-Tyr et L-Leu. Ces composés ont été testés en solution à $0,3 \%$ dans l'eau à $\mathrm{pH} 6$ (ajusté par $\mathrm{NaOH}$ et $\mathrm{HCl}$ ) et l'on peut penser que certains acides aminés, trouvés fades, sont également amers mais ont un seuil de détection plus élevé. L'amertume des acides aminés a été comparée à celle de solutions de caféine de concentration connue. L'auteur a pu montrer que, dans ces conditions, le tryptophane et la phénylalanine sont, respectivement, deux fois et quatre fois moins amers que la caféine. La tyrosine et la leucine sont quant à elles 18 et 27 fois moins amères que la caféine.

Kato et al (1989) trouvent, quant à eux, neuf acides aminés amers. Les seuils de détection obtenus sont reportés dans le tableau II. Les auteurs observent que ce sont les acides aminés hydrophobes qui ont une saveur amère. Toutefois, ils précisent que cela n'est vrai que pour les énantiomères $L$.

D'après Haefeli et Glaser (1990) la saveur amère est la seule détectée pour L-Leu, L-lle, L-Arg, L-Phe, L-Trp et L-His. Toutefois le goût de certains acides aminés est plus complexe et l'amertume est également détectée pour certains acides aminés sucrés ou salés : L-Val, L-Ser, L-Asn, L-Gln, L-Lys, L-Cys, L-Met, L-Pro. Ces observations ont été faites en goûtant les acides aminés en poudre. En fait, la proline, la cystéine et la sérine perdent cette amertume en solution (tableau II).

\section{Les acides aminés sucrés}

En ce qui concerne les acides aminés sucrés, Solms (1969) en a également trouvé quatre. La L-proline et la L-méthionine sont légèrement sucrés tandis que des solutions à $0,3 \%$ d'alanine et de glycine sont aussi sucrées que des solutions de saccharose à 0,54 et $0,45 \%$, respectivement. Toutefois, il ne s'agit pas des seuls acides 
Tableau I. Qualités organoleptiques des acides aminés d'après sept équipes différentes d'après Schiffman et Engelhard, 1976.

The taste qualities for amino acids from seven different studies, from Schiffman and Engelhard, 1976.

\begin{tabular}{|c|c|c|c|c|c|c|c|c|}
\hline & $\begin{array}{l}\text { Schiffman } \\
\text { et Dackis, } 1975\end{array}$ & $\begin{array}{l}\text { Meister, } \\
1965\end{array}$ & $\begin{array}{l}\text { Shallenberger } \\
\text { et Acree, } 1971\end{array}$ & $\begin{array}{l}\text { Yoshida et } \\
\text { Saito, } 1969\end{array}$ & Berg, 1953 & $\begin{array}{l}\text { Solms et al, } \\
\quad 1965\end{array}$ & $\begin{array}{c}\text { Schiffman et } \\
\text { Engelhard, } \\
1976\end{array}$ & Conclusion \\
\hline Glycine & Sucré, agréable & & Sucré & Sucré & & Sucré & & Sucré \\
\hline Alanine & $\begin{array}{l}\text { Sucré, arrière-goût } \\
\text { proche saccharine }\end{array}$ & Sucré & Sucré & $\begin{array}{l}\text { Sucré, } \\
\text { umami }\end{array}$ & & Sucré & & $\begin{array}{l}\text { Sucré, complexe avec } \\
\text { amertume et arrière-goût }\end{array}$ \\
\hline Valine & $\begin{array}{l}\text { Fade, salé, } \\
\text { légèrement amer et } \\
\text { peu être sucré }\end{array}$ & Fade, amer & Sucré, amer & Amer, sucré & $\begin{array}{l}\text { Légèrement } \\
\text { sucré, amer }\end{array}$ & Fade & & $\begin{array}{l}\text { Fade à amer, légèrement } \\
\text { sucré }\end{array}$ \\
\hline Leucine & Fade, désagréable & Fade, amer & Amer & Amer & Fade & Amer & & Fade à amer \\
\hline Isoleucine & Fade, désagréable & Amer & Amer & Amer & $\begin{array}{l}\text { Amer, } \\
\text { légèrement } \\
\text { astringent }\end{array}$ & Fade & & Fade à amer \\
\hline Sérine & Sucré & $\begin{array}{l}\text { Légèrement } \\
\text { sucré }\end{array}$ & Sucré & $\begin{array}{l}\text { Sucré, peut } \\
\text { être acide, } \\
\text { umami }\end{array}$ & $\begin{array}{l}\text { Légèrement } \\
\text { sucré, } \\
\text { arrière-goût } \\
\text { éventé }\end{array}$ & Fade & & $\begin{array}{l}\text { Fade à sucré, peut être acide, } \\
\text { complexe }\end{array}$ \\
\hline Thréonine & $\begin{array}{l}\text { Légèrement sucré, } \\
\text { doux, légèrement gras }\end{array}$ & $\begin{array}{l}\text { Légèrement } \\
\text { sucré }\end{array}$ & Sucré, amer & Sucré, acide & $\begin{array}{l}\text { Légèrement } \\
\text { sucré }\end{array}$ & Fade & & $\begin{array}{l}\text { Fade à sucré, peut être } \\
\text { amer, acide ou gras }\end{array}$ \\
\hline Cystéine & Sulfureux & & & & & Sulfureux & & Sulfureux \\
\hline Méthionine & Amer, désagréable & Fade & Sans goût & Amer & Fade & $\begin{array}{l}\text { Sulfureux, } \\
\text { viande, } \\
\text { légèrement sucré }\end{array}$ & & $\begin{array}{l}\text { Fade à amer, peut être } \\
\text { sulfureux, viande ou sucré }\end{array}$ \\
\hline Ac aspartique & Acide & $\begin{array}{l}\text { Légèrement } \\
\text { amer }\end{array}$ & & Acide & & Fade & & $\begin{array}{l}\text { Fade, acide, légèrement } \\
\text { amer }\end{array}$ \\
\hline Asparagine & & Fade, amer & Sans goût & & Insipide & Fade & & Fade à amer \\
\hline
\end{tabular}


Tableau I (suite)

\begin{tabular}{|c|c|c|c|c|c|c|c|c|}
\hline & $\begin{array}{c}\text { Schiffman } \\
\text { et Dackis, } 1975\end{array}$ & Meister, 1965 & $\begin{array}{l}\text { Shallenberger } \\
\text { et Acree, } 1971\end{array}$ & $\begin{array}{l}\text { Yoshida et } \\
\text { Saito, } 1969\end{array}$ & Berg, 1953 & $\begin{array}{l}\text { Solms et al, } \\
1965\end{array}$ & $\begin{array}{l}\text { Schiffman et } \\
\text { Engelhard, } \\
1976\end{array}$ & Conclusion \\
\hline Ac glutamique & & Viande & Sans goût & Acide, umami & Particulier & $\begin{array}{l}\text { Particulier, } \\
\text { glutamate }\end{array}$ & $\begin{array}{l}\text { Salé, amer, } \\
\text { peut être acide }\end{array}$ & $\begin{array}{l}\text { Particulier, peut } \\
\text { être viande, } \\
\text { salé, amer }\end{array}$ \\
\hline Glutamine & $\begin{array}{l}\text { Sucré, viande, } \\
\text { légèrement } \\
\text { désagréable }\end{array}$ & Fade & & & & & & $\begin{array}{l}\text { Acide, } \\
\text { complexe, fade, } \\
\text { sucré, viande, } \\
\text { parfois } \\
\text { désagréable }\end{array}$ \\
\hline Arginine & $\begin{array}{l}\text { Piquant, alcalin, } \\
\text { amer, complexe }\end{array}$ & & & Amer & & Fade & & $\begin{array}{l}\text { Fade à amer, } \\
\text { alcalin, complexe }\end{array}$ \\
\hline Lysine & & & & & & Fade & $\begin{array}{l}\text { Complexe, } \\
\text { minéral }\end{array}$ & $\begin{array}{l}\text { Fade, complexe, } \\
\text { minéral }\end{array}$ \\
\hline Lysine, $\mathrm{HCl}$ & Amer, salé & & & Amer, sucré & & & & $\begin{array}{l}\text { Amer, } \\
\text { complexe, salé, } \\
\text { sucré }\end{array}$ \\
\hline Histidine & & Fade, amer & Sans goût & $\begin{array}{l}\text { Amer, peut être } \\
\text { sucré }\end{array}$ & Fade à amer & Fade & $\begin{array}{l}\text { Léger, amer, } \\
\text { minéral }\end{array}$ & $\begin{array}{l}\text { Fade à amer, } \\
\text { minéral }\end{array}$ \\
\hline Phénylalanine & Amer, complexe & $\begin{array}{l}\text { Légèrement } \\
\text { amer }\end{array}$ & Amer & Amer & $\begin{array}{l}\text { Légèrement } \\
\text { amer }\end{array}$ & Amer & & $\begin{array}{l}\text { Amer, peut être } \\
\text { complexe }\end{array}$ \\
\hline Tyrosine & Fade & Fade, amer & Amer & & Amer & Amer & & Fade à amer \\
\hline Tryptophane & Amer & Fade & Sans goût & Amer & Fade & Amer & & Fade à amer \\
\hline Proline & $\begin{array}{l}\text { Complexe, salé, } \\
\text { acide, peut être } \\
\text { sucré }\end{array}$ & & Sucré & Sucré, amer & & $\begin{array}{l}\text { Fade, } \\
\text { légèrement } \\
\text { sucré }\end{array}$ & & $\begin{array}{l}\text { Sucré, peut être } \\
\text { complexe avec } \\
\text { composés salés } \\
\text { ou acides }\end{array}$ \\
\hline
\end{tabular}


aminés sucrés. En effet, tout comme les acides aminés hydrophobes de configuration L- étaient amers, leurs homologues de configuration D- sont sucrés avec un pouvoir sucrant supérieur à celui du saccharose. Ainsi, si la D-Leu n'est que 4,3 fois plus sucrée que le saccharose, et D-Phe, D-His, D-Tyr 6 à 7 fois, le D-Trp atteint un pouvoir sucrant 36 fois plus important.

D'après Kato et al (1989), six acides aminés de configuration L-sont sucrés. Parmi eux, la lysine et la proline ont un arrièregoût amer.

Haefeli et Glaser (1990) trouvent à peu près les mêmes résultats. Toutefois, ils mettent en évidence de petites différences selon les conditions de dégustation. La sérine, par exemple, sucrée en solution, possède une saveur beaucoup plus complexe lorsqu'elle n'est pas dissoute. On observe ainsi, que les résultats obtenus sont dépendants des conditions de dégustation. II est donc indispensable de les détailler.

Comme nous l'avons précisé plus haut, la glycine est un acide aminé sucré. Présente en quantité importante dans la gélatine $(25,5 \%)$, elle peut être utilisée comme édulcorant ; Stanley (1981) a montré qu'elle pouvait également masquer l'amertume de certains hydrolysats. D'autre part, la saveur sucrée des acides aminés peut être intensifiée en présence de $\mathrm{NaCl}$ lorsque celui-ci est utilisé à des concentrations inférieures au seuil de détection du goût salé (Ugawa et al, 1992).

Contrairement aux acides aminés amers, la polarité ne semble pas être un élément essentiel pour l'obtention d'un goût sucré : Thr et Ser sont polaires, Gly et Ala sont neutres et les acides aminés sucrés de configuration D sont hydrophobes.

\section{Les acides aminés salés}

D'après le tableau II, seule la glutamine en poudre possède une saveur salée. Pourtant, d'après le tableau de Schiffman et Engelhard (tableau I), des saveurs salées ont été détectées pour la lysine- $\mathrm{HCl}$, la proline et l'acide glutamique. Les différences observées peuvent provenir des conditions de préparation des échantillons.

\section{Les acides aminés acides}

Seuls les acides aminés acides, tels que Asp et Glu ont, sous leur forme dissociée, une saveur acide qui serait due à l'interaction des protons des groupements acides avec les cellules du goût (Nishimura et Kato, 1988).

\section{Les acides aminés umami}

Ils sont représentés par les sels de sodium des acides aminés acides Asp et Glu. Ce " nouveau goût ", que l'on peut définir comme un goût de bouillon de poule, légèrement salé, et dont le nom japonais " umami " signifie " délicieux " est représenté par le glutamate de sodium (MSG). Sa distribution dans divers aliments est donnée dans le tableau III. Dans des fromages de type Herrgard et Drabant de 14 semaines, Ardö et Gripon (1995) ont obtenu des quantités d'acide glutamique variant entre 0,5 et $0,9 \%$. Le MSG est utilisé comme additif pour de nombreux aliments (Rhodes et al, 1991) : soupes, sauces, viandes, poissons, à des concentrations de 0,1 à $0,9 \%$.

La relation entre la structure et le goût du MSG a été étudiée : outre la présence indispensable du sodium, il a été observé que son goût « umami » disparaît par acétylation du groupement aminé, par estérification du groupement carboxylique et par remplacement de l'hydrogène $\alpha$ par un groupement méthyle (Nishimura et Kato, 1988). Ainsi, la formation d'un cycle à cinq liaisons, par des forces électrostatiques entre le $\alpha-\mathrm{NH}_{3}{ }^{+}$et le $\gamma-\mathrm{CO}_{2}^{-}$, semble jouer un rôle important dans l'apparition du goût " umami " du MSG (fig 2). Le goût " uma$\mathrm{mi}$ » est souvent lié à la présence de 5'ribonucléotides (Yamaguchi, 1991). Ces 
Tableau II. Goûts et seuils de détection des acides aminés d'après trois équipes différentes, et dans des conditions différentes (en solution ou sous forme de cristaux).

Taste qualities and threshold values of amino acids from three different studies, in different conditions (directly from cristals or in solution).

\begin{tabular}{|c|c|c|c|c|c|}
\hline \multirow{2}{*}{$\begin{array}{l}\text { Acide } \\
\text { aminé } \\
\text { Configu } \\
\text { ration }\end{array}$} & \multicolumn{2}{|c|}{ Solms $(1969)^{1}$} & \multirow{2}{*}{$\begin{array}{c}\text { Kato et al }(1989)^{2} \\
\text { L- }\end{array}$} & \multicolumn{2}{|c|}{ Haefeli et Glaser $(1990)^{3}$} \\
\hline & L- & $D$ - & & L- & $D$ - \\
\hline Gly & \multicolumn{2}{|c|}{ Sucré $(0,45 \% \mathrm{sac})^{4}$} & Sucré (130) & \multicolumn{2}{|l|}{ Sucré } \\
\hline Ala & Sucré $(0,54 \%$ sac $)$ & & Sucré $(60)$ & Sucré & Sucré \\
\hline lle & -5 & 一 & Amer (90) & Amer & Sucré-(Amer) \\
\hline Leu & $\operatorname{Amer}(0,011 \% \text { caf. })^{6}$ & Sucré $(1,30 \%$ sac $)$ & Amer (190) & Amer & Sucré \\
\hline Val & 一 & 一 & Amer (40) & (Sucré) - Amer & Sucré \\
\hline Ser & 一 & 一 & Sucré (150) & Sucré-(Amer-Acide) & Sucré \\
\hline Thr & 一 & 一 & Sucré (260) & Sucré & Sucré \\
\hline Asn & & & Acide (100) & Amer-Sucré & Sucré \\
\hline Gin & & & 一 & (Salé $\rightarrow$ Sucré)-Amer & Sucré \\
\hline Asp & 一 & 一 & Acide $\left(\right.$ Umami) $^{7}(3 ; 100)$ & Acide & Acide \\
\hline Glu & "Glutamate" & 一 & Acide $\left(\right.$ Umami $^{7}(5 ; 30)$ & Acide & Acide \\
\hline Arg & 一 & Lég Sucré & Amer (50) & Amer & Sucré-(Amer) \\
\hline Lys & 一 & 一 & Sucré et Amer (50) & Sucré-Amer & Sucré-(Amer) \\
\hline Cys & Soufré & Soufré & & (Amer)-Sucré & $\begin{array}{c}\text { Sucré- } \\
\text { (Amer-Acide) }\end{array}$ \\
\hline Met & Soufré, lég Sucré & Soufré, lég sucré & Amer (30) & Amer-Sucré & Sucré \\
\hline Phe & Amer $(0,069 \%$ caf $)$ & Sucré $(2,20 \%$ sac) & Amer (90) & Amer & Sucré-(Amer) \\
\hline Tyr & Amer $(0,017 \%$ caf $)$ & Sucré $(1,65 \%$ sac $)$ & Amer & $-(\rightarrow$ Amer $)$ & - $(\rightarrow$ Sucré $)$ \\
\hline Trp & $\operatorname{Amer}(0,133 \%$ caf $)$ & Sucré $(11,00 \% \mathrm{sac})$ & Amer (90) & Amer & Sucré \\
\hline His & 一 & Sucré $(2,23 \%$ sac $)$ & Amer (20) & Amer & Sucré \\
\hline Pro & Lég Sucré & - & Sucré et Amer $(300)$ & Sucré-(Amer) & Amer-(Acide) \\
\hline
\end{tabular}

${ }^{1}$ En solution à pH 6, ajusté par $\mathrm{NaOH}$ ou $\mathrm{HCl} ;{ }^{2}(\mathrm{x})$ : seuil de détection en $\mathrm{mg} / \mathrm{dL} ;{ }^{3}$ Dégustation sur les cristaux directement. (amer) : descriptif disparaissant en solution. (Amer $\rightarrow$ Sucré) : descriptif différent en solution $;{ }^{4} \mathrm{X} \% \mathrm{sac}$ : Comparable à une solution à $\mathrm{X} \%$ de saccharose $;{ }^{5}$ — : sans goût, plat, fade; ${ }^{6} \mathrm{X} \%$ caf. : comparable à une solution à $\mathrm{X} \%$ de caféine ; ${ }^{7}$ Umami pour Glu $\mathrm{Na}$ et Asp $\mathrm{Na}$.

${ }^{1}$ In a solution at $\mathrm{pH} 6$ adjusted by $\mathrm{NaOH}$ or $\mathrm{HCl}^{2}{ }^{2}(X)$ : threshold value in $\mathrm{mg} / \mathrm{dL} ;{ }^{3}$ tasted on cristals. (Amer): taste desappearing when tasted in solution. (Amer $\rightarrow$ Sucré): taste is different from cristals to solution: ${ }^{4} \mathrm{X} \%$ sac: in comparison to a solution containing $X \%$ of saccharose; ${ }^{5}$ - tasteless; ${ }^{6} \mathrm{X} \%$ caf: in comparison to a solution containing $X \%$ of caffeine; ${ }^{7}$ Umami for GluNa and AspNa. 


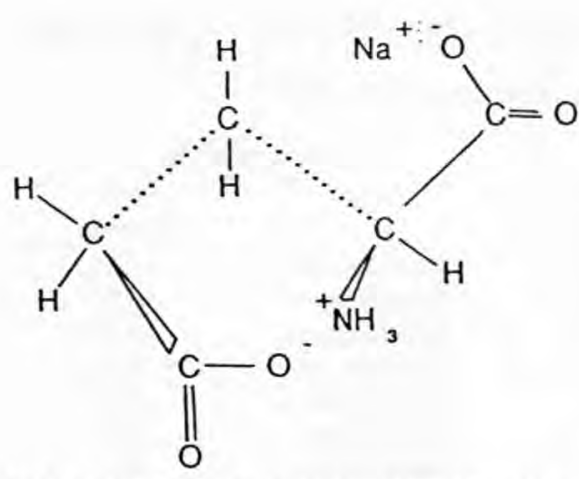

Fig 2. Structure tridimensionnelle du monoglutamate de sodium (MSG).

Three-dimensional structure of monosodium glutamate (MSG).

Tableau III. L-Glutamate libre dans les aliments naturels d'après Kato et al, 1989.

Free L-glutamate in natural foods from Kato et al, 1989.

\begin{tabular}{lc}
\hline Aliment & $\begin{array}{c}\text { L-Glutamate } \\
(\mathrm{mg} / 100 \mathrm{~g})\end{array}$ \\
\hline Varech & 2240 \\
Parmesan & 1200 \\
Thé vert & 668 \\
Algues & 640 \\
Sardine fraîche & 280 \\
Jus de tomate frais & 260 \\
Champignon & 180 \\
Tomate & 140 \\
Huître & 137 \\
Pomme de terre & 102 \\
Chou chinois & 100 \\
Shiitake frais (champignon) & 67 \\
Soja & 66 \\
Pomme de terre sucrée & 60 \\
Sardine grillée & 50 \\
Crevette & 43 \\
Palourde & 41 \\
Os de poulet & 40 \\
Chou & 37 \\
Carotte & 33 \\
Filet de porc & 23 \\
\hline
\end{tabular}

derniers, umami, participent avec le MSG à l'intensification de la flaveur des aliments (Maga, 1983). Ce phénomène de synergie est également intensifié en présence d'acides aminés tels que Ala, Cys, His, Met, Pro, Val, et Gly (Yokotsuka, 1969 et Tanaka, 1969 cités par Kato et al, 1989). Ainsi, Nagai et al (1994) ont obtenu du Natto (produit fermenté, non salé à base de soja) ayant un goût umami très fort, uniquement en doublant le nombre d'acides aminés libres par l'utilisation d'une souche particulière de $B$ subtilis. L'acide glutamique libre avait augmenté de $67 \%$. Le MSG est souvent assimilé à un exhausteur de flaveurs. Une étude récente (Kemp et Beauchamp, 1994) a toutefois montré que si le MSG peut modifier une flaveur, quantitativement ou qualitativement, il provoque plutôt une diminution globale de la flaveur. Cependant, par un effet de déséquilibre, certaines flaveurs peuvent alors apparaître, de manière relative, plus importantes.

Ainsi, nous avons vu que la plupart des acides aminés sont amers ou sucrés. Toutefois, des essais de désamèrisation des acides aminés (Tamura et al, 1990) ont montré qu'un blocage du $\mathrm{N}$-terminal par une acétylation ou une liaison peptidique peut donner des saveurs acides ou salé /umami (tableau IV). D'autre part, les acides aminés semblent avoir un fort potentiel de synergie. Ainsi, si les acides aminés ont longtemps été utilisés pour augmenter la valeur nutritive des aliments, ils sont, de nos jours, également utilisés pour leur propriété à intensifier les caractéristiques organoleptiques des aliments.

\section{LE GOÛT DES PEPTIDES}

Les études portant sur le goût des peptides sont plus récentes que celles portant sur le goût des acides aminés. Il a été montré que le goût amer apparaissant au cours de l'affinage des fromages et pendant la fermentation des produits traditionnels japonais (miso, sauce de soja...) est causé par les 
Tableau IV. Influence des sels de sodium sur le goût de composés acides (acides aminés $\mathrm{N}$-acétylés et dipeptides) d'après Tamura et al, 1990.

Impact of sodium salts on the taste of sour molecules from Tamura et al, 1990.

\begin{tabular}{|c|c|c|c|c|}
\hline \multirow[t]{2}{*}{ Composé } & \multicolumn{2}{|c|}{ Sans sels } & \multicolumn{2}{|c|}{ Avec sels de $\mathrm{Na}$} \\
\hline & Goût & $\begin{array}{c}\text { Seuil } \\
\text { (mmol/L) }\end{array}$ & Goût & $\begin{array}{c}\text { Seuil } \\
(\mathrm{mmol} / \mathrm{L})\end{array}$ \\
\hline Ac-Val & Acide & 0,94 & Salé/Umami & 15,0 \\
\hline Ac-Leu & Acide & 0,47 & Salé/Umami & 15,0 \\
\hline Ac-\|le & Acide & 0,94 & Salé/Umami & 15,0 \\
\hline Glu-Val & Acide & - & Salé/Umami & 5,0 \\
\hline Glu-Leu & Acide & - & Salé/Umami & 5,0 \\
\hline Glu-Ile & Acide & - & Salé/Umami & 3,3 \\
\hline Asp-Val & Acide & - & Salé/Umami & 8,1 \\
\hline Asp-Leu & Acide & - & Salé/Umami & 3,3 \\
\hline Asp-lle & Acide & - & Salé/Umami & 5,3 \\
\hline
\end{tabular}

Ac-X: Acétylation du N-terminal ; N-terminal acetylation.

peptides présents dans les hydrolysats de protéines. Par conséquent, un certain nombre de travaux se sont orientés vers les peptides amers. Les recherches sur les peptides sucrés et " umami " ne sont apparues que très récemment. Ces travaux ont, en général, porté sur des peptides synthétiques. Le rôle de ces peptides dans les aliments n'a pas encore été clairement élucidé. Nous ferons, toutefois, dans les pages qui suivent, un état des connaissances sur la relation goût-peptide et sur l'impact de ces composés sur la flaveur des aliments.

\section{Les peptides sucrés}

\section{Théorie du goût sucré}

La première théorie concernant le goût sucré a porté sur les sucres. Shallenberger et Acree (1967) ont mis en évidence deux sites $\mathrm{AH}$ et $\mathrm{B}$ indispensables pour avoir une saveur sucrée. A et $B$ sont des atomes électronégatifs et ils sont séparés par une distance pouvant varier de 2,5 à $4 \AA$. H est un atome d'hydrogène attaché à l'un des atomes électronégatifs par une liaison covalente. Ainsi, un composé sucré doit posséder un hydrogène légèrement acide. En général, $A$ et $B$ sont soit de l'oxygène, soit de l'azote, mais également un atome de carbone ou de chlore ou encore un centre d'insaturation. Ainsi, dans le cas de l'alanine dont les formes $L$ et $D$ sont toutes deux sucrées, le groupement $\mathrm{NH}_{3}{ }^{+}$est le centre $\mathrm{AH}$, donneur de proton, et le $\mathrm{CO}_{2}{ }^{-}$est le site accepteur de proton. La distance A-B est de $3 \AA$, et l'interaction est possible car la chaîne carbonée est courte. Si l'on regarde la distance du proton à $\mathrm{B}$, elle semble plus significative et est de $3 \AA$ en moyenne pour tous les composés sucrés. Si la molécule sucrée est dotée d'un système bifonctionnel, le site récepteur doit également posséder un système de type $\mathrm{AH}-\mathrm{B}$, afin d'obtenir une interaction " concertée " mettant en jeu deux liaisons hydrogènes.

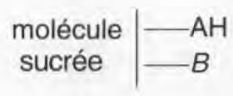

$$
\begin{array}{r|r|}
B^{\prime}- & \text { récepteur } \\
H A^{\prime}- & \text { res }
\end{array}
$$

Le goût sucré de l'aspartame (Asp-PheOMe) peut être expliqué par la théorie de Shallenberger et Acree. Mais des études sur l'aspartame et quelques analogues ont montré qu'un troisième site, un groupement hydrophobe $X$, participait à la production de la saveur sucrée (Shinoda et Okai, 1985). Ainsi, le goût sucré de l'aspartame 
proviendrait de la présence simultanée d'un site $\mathrm{AH}$ électropositif ( $\alpha$-amino), d'un groupement $B$ électronégatif ( $\beta$-carboxyle) et un groupement hydrophobe $X$ (méthylester) situé sur la chaîne carbonée du résidu Phe. Cette unité trifonctionnelle interagit avec les récepteurs des bourgeons du goût (AH', B', X') (fig 3). Cette explication permet alors de se demander ce qui se passerait si les trois sites n'appartenaient pas tous à la même molécule. Les conclusions de cette étude sont les suivantes : une substance sucrée possède trois sites $A H, B, X$; parmi ces trois sites, $\mathrm{AH}-\mathrm{X}$ correspond à la production d'amertume; l'amertume peut être transformée en saveur sucrée si l'on rajoute une molécule contenant un site $B$ (fig 3, type a), elle peut être éliminée si l'on rajoute une molécule à site $X-B$.

La recherche de composés sucrés dérivant de l'aspartame (APM) a montré (Zeng et al, 1991) que pour obtenir un goût sucré, dans le cas d'une molécule telle que :

$$
\mathrm{L} \text { - Asp - NH - } \mathrm{CH}\left(\mathrm{R}_{1}\right)-\mathrm{CO}-\mathrm{R}
$$

II faut que $R$ soit plus grand que $R 1$ et pour une intensité maximale, il faut que $R$ ait six carbones. De plus, pour $\mathrm{R}$ donné, l'intensité décroît pour $\mathrm{R}_{1}=\mathrm{CO}_{2} \mathrm{Me}>\mathrm{CO}_{2} \mathrm{Et}>$ $\mathrm{CH}_{2} \mathrm{OH}>\mathrm{CHMeOH}>\mathrm{Me}>\mathrm{Et}>\mathrm{i}-\mathrm{Pr}$. Ces règles ont permis aux auteurs de synthétiser des composés 50000 fois plus sucrés que le saccharose (à masse égale).

\section{Exemples de peptides sucrés}

Le peptide sucré le plus utilisé de nos jours est l'aspartame (Asp-Phe-OMe), découvert par Mazur et al en 1969 (fig 4). L'aspartame (APM) est 180 fois plus sucré que le saccharose, il est stable à $\mathrm{pH} 4$ et instable à $\mathrm{pH} 1$ ou 7-8. II est également instable à la chaleur. Dans ces conditions, il y a hydrolyse de la liaison ester et formation d'un dipeptide Asp-Phe linéaire ou cyclisé (dicétopipérazine) et de méthanol. Aucun de ces produits de décomposition n'obéit à la règle $\mathrm{AH}-\mathrm{B}-\mathrm{X}$ et aucun d'entre eux n'a un

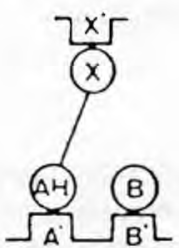

type a

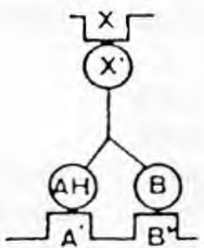

$\triangle P M$

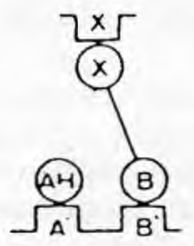

type b
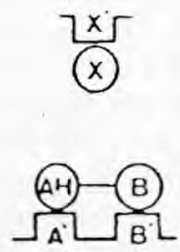

type $c$

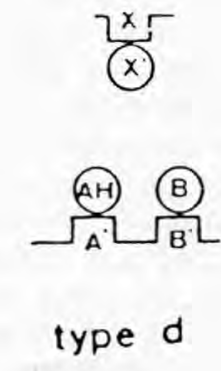

Fig 3. La production de goût sucré par l'aspartame: interactions entre les sites $\mathrm{AH}, \mathrm{B}, \mathrm{X}$ de la molécule sucrée et AH', B', X' du récepteur. Type a : sucré ; types b, c, d : non sucré (Shinoda et Okai, 1985). The production of sweetness of aspartame caused by the interaction between three sweet units $(A H$, $B, X)$ and the corresponding receptor sites $\left(A H^{\prime}, B^{\prime}, X^{\prime}\right)$ (Shinoda and Okai, 1985). 
goût sucré. Une étude est en cours sur le mécanisme de dégradation de l'APM en présence de macromolécules telles que les caséines (Tsoubeli et Labuza, 1992)

La découverte de l'aspartame a donné lieu à de nombreuses études sur ses dérivés et leurs goûts. Ainsi, King et al (1991) ont étudié une nouvelle série d'édulcorants, dans lesquels ils ont remplacé le cycle phényle de l'APM par une unité bicycloalkyle substituée. Des composés ayant des seuils 2000 fois plus faibles que le saccharose ont été obtenus : (Asp-3 (2bornyl)-AlaOMe).

L'instabilité de l'aspartame est un gros problème au niveau des applications. Boesten et al (1991) ont synthétisé un composé dérivé de l'APM, aussi sucré que I'APM, mais plus stable. Le $\mathrm{N}$-formyl-carbamoyl-aspartame (FCAPM) est 200 fois plus intense que le saccharose. Ce résultat est surprenant quand on sait que la plupart des composés dérivés de l'APM sont amers ou dénués de goût. De plus, le carbamoyl-aspartame (CAPM) qui est intermédiaire entre APM et FCAPM est lui-même dénué de goût.

Un autre composé dérivé de l'APM a été synthétisé par Ota et al (1993) : ainsi, l'acide aspartique de l'APM a été remplacé par un groupement amino-malonyl (Ama) sans altérer le pouvoir sucrant. En effet, les auteurs ont trouvé que (R)Ama- (S)PheOMe est 800 fois plus sucré qu'une solution de saccharose à $0,6 \%$. (R)Ama- (S)PheOEt est quant à lui 50 fois plus sucré que la même solution de saccharose.

L'aspartame n'est pas le seul peptide sucré ayant attiré l'attention. Ainsi, lors d'études sur les peptides salés, Tada et al (1984) ont montré que les dipeptides basiques Gly-Lys et $\gamma$-Abu-Lys avaient une saveur sucrée proche de celle du saccharose (Abu : acide amino butyrique). Par comparaison avec l'APM, Nosho et al (1990) ont associé les $\varepsilon-\mathrm{NH}_{2}, \alpha-\mathrm{CO}_{2} \mathrm{H}$ et le résidu $\mathrm{N}$-terminal aux sites $\mathrm{AH}, \mathrm{B}, \mathrm{X}$ (fig 4). Ainsi, en ajoutant un fragment hydrophobe en $\mathrm{N}$ terminal, un benzoyle par exemple, on
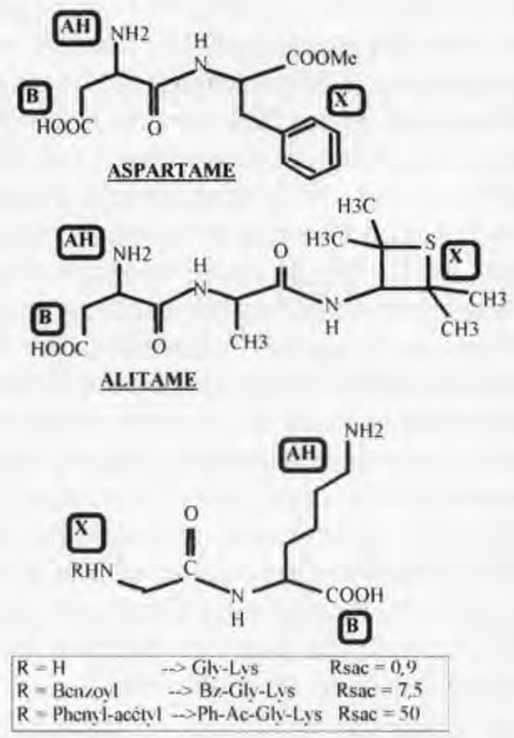

Fig 4. Comparaison des structures de diverses molécules sucrées : détermination des sites $\mathrm{AH}$, $\mathrm{B}, \mathrm{X}$.

Comparison of some sweet molecule structures: determination of the sites $A H, B, X$.

remarque que le peptide Bz-Gly-Lys est sucré et possède un seuil de détection 7,5 fois plus faible que celui du saccharose, la phénylacétyl-Gly-Lys et Ac-Phe-Lys étant quant à eux 50 et 23 fois plus sucrés que le saccharose. De cette façon, la théorie AH-B-X développée pour l'aspartame est vérifiée et les auteurs ont pu obtenir des composés 50 fois plus sucrés que le saccharose. Un peptide sucré de structure semblable a été synthétisé par voie enzymatique par Aso (1989) : N-Ac-Phe-Lys. Séki et al (1990) ont montré que les trois sites $\mathrm{AH}, \mathrm{B}, \mathrm{X}$ ne sont pas forcément localisés sur la même molécule. Ainsi le peptide $\delta$-Ac-Orn- $\beta A$ la, légèrement sucré $\left(R_{\text {saccha. }}\right.$ rose $=0,7)$ en solution a un pouvoir sucrant plus important $\left(R_{\text {saccharose }}=1,8\right)$ si l'on rajoute $\mathrm{HCl}$, qui joue alors le rôle du site $\mathrm{B}$, dans le milieu. 
Outre l'aspartame et ses nombreux dérivés, un autre dérivé de dipeptide a été mis sur le marché récemment. L'alitame (Pfizer) ou hydrate $(2,5)$ de la L-aspartyl-N(2,2,4,4-tetraméthyl-3-thiétanyl)-D-alanin -amide (fig 4) est environ 2000 fois plus sucré que le saccharose en solution à $10 \%$ et 2900 fois lorsqu'il est comparé à du saccharose à $2-3 \%$. C'est un composé hypocalorique, beaucoup plus stable que l'APM et dont les produits de dégradation sont totalement insipides étant donné les faibles quantités ajoutées aux aliments (Anonyme, 1987).

\section{Les peptides amers}

\section{Relation amertume-hydrophobicité}

Nous avons vu que la plupart des acides aminés hydrophobes ont un goût amer. Presque tous les peptides formés par ces acides aminés (L-Phe, L-Tyr, L-Trp, L-Leu, L-Val, L-Ile) sont également amers. Cela indique que l'amertume d'un peptide est dépendante des propriétés hydrophobes des acides aminés le constituant (Kato et

Tableau V. Énergies libres de transfert (hydrophobicité) des chaînes carbonées des acides aminés.

Free energy of transfer (hydrophobicity) of the side chain of the amino acid residues.

\begin{tabular}{cc}
\hline Acide aminé & $\Delta f(\mathrm{cal} / \mathrm{mol})$ \\
\hline Gly & 0 \\
Ala & 730 \\
Val & 1690 \\
Leu & 2420 \\
Ile & 2970 \\
Phe & 2650 \\
Pro & 2600 \\
Met & 1300 \\
Tyr & 2870 \\
Thr & 440 \\
Ser & 40 \\
Asp & 540 \\
Glu & 550 \\
Arg & 730 \\
Lys & 1500 \\
Trp & 3000 \\
\hline
\end{tabular}

al, 1989). D'après Ney (1971), on peut prédire si un peptide sera amer ou pas selon la valeur $Q$ de l'hydrophobicité (fig 5 , tableau V). La valeur $Q$ est la moyenne des énergies libres de transfert $\left(\Delta \mathrm{f}_{\mathrm{t}}\right.$ ) de l'éthanol dans l'eau des acides aminés constituant le peptide (Adler-Nissen, 1986). Ney trouve que les peptides amers ont une valeur d'hydrophobicité moyenne supérieure à 1400 calories par mole $(5,86 \mathrm{~kJ})$, tandis que les peptides non amers ont une valeur inférieure à $1300 \mathrm{cal} / \mathrm{mol}(5,44 \mathrm{~kJ})$. Cette règle a été très largement controversée par Guigoz et Solms (1976), qui ont comparé la valeur $Q$ au goût de 206 peptides.

Les résultats montrent que si la majorité des peptides amers ont une valeur $Q$ supérieure à $1300 \mathrm{cal} / \mathrm{mol}$, certains d'entre eux, contenant par exemple de la glycine, n'obéissent pas à cette loi. Les auteurs ont alors proposé de ne pas compter les résidus glycine (pas de chaîne carbonée, hydrophobicité négligeable) ; ainsi, la majorité des peptides amers aura une hydrophobicité moyenne supérieure à 1300 $\mathrm{cal} / \mathrm{mol}$. Mais cette règle n'est encore qu'une approximation car si l'on considère la gélatine qui contient environ un tiers de glycine, les peptides provenant de son hydrolyse devraient avoir une hydrophobicité supérieure à $1300 \mathrm{cal} / \mathrm{mol}$; or, aucun peptide amer n'a été, à ce jour, rapporté pour cette protéine.

\footnotetext{
Solubilité de l'acide aminé dans l'eau: $\mathrm{N}_{\mathrm{HzO}}$ Solubilité de l'acide aminè dans l'èthanol: $\mathrm{N}_{\mathrm{ELOH}}$

Fig 5. Définition de l'hydrophobicité moyenne Q (d'après Ney, 1971).

Definition of average hydrophobicity. 


\section{Relation amertume-structure}

En 1972, Matoba et Hata ont suggéré que non seulement l'hydrophobicité intervenait dans l'amertume mais également la séquence du peptide. En effet, le blocage d'une extrémité $\mathrm{C}$ - ou $\mathrm{N}$ - terminale, c'està-dire par exemple la formation d'une liaison peptidique, augmente l'amertume. Belitz et Wieser (1976) ont montré que l'interaction du groupement $\mathrm{N}$-terminal avec un récepteur nucléophile distant de $3 \AA$ donnait lieu à de l'amertume, mais si le carboxyle pouvait également interagir, cela donnait lieu à une saveur sucrée. Ces dernières observations sont en accord avec les résultats de Shinoda et Okai (1985) à propos du mécanisme de formation des goûts amers et sucrés. En effet, nous l'avons vu précédemment, le goût sucré est obtenu en superposant les sites AH-B-X d'une ou plusieurs molécules aux sites correspondants du récepteur. Lorsque le site $\mathrm{B}$ est absent, les sites $\mathrm{AH}-\mathrm{X}$ sont responsables de la saveur amère.

Ainsi, il est possible de transformer facilement une saveur amère en saveur sucrée en ajoutant dans le milieu une molécule faisant acte de site $B$. On peut également faire baisser l'amertume ou la faire disparaître en ajoutant dans le milieu une molécule possédant les sites X-B.

La présence des deux sites $\mathrm{AH}-\mathrm{X}$, a été confirmée récemment par des auteurs coréens (Yeom et al, 1994) qui ont désamèrisés un hydrolysat de protéine en acétylant les lysines. Le groupement $\mathrm{AH}\left(\varepsilon-\mathrm{NH}_{2}\right)$ étant bloqué, les interactions nécessaires au développement de l'amertume n'existent plus et l'amertume diminue, bien que l'hydrophobicité de surface de l'hydrolysat soit plus forte. Okaï, en 1977, avait montré que l'amertume des peptides apparaissait lorsque des unités bifonctionnelles (l'une étant la fonction basique ou la chaîne latérale d'un acide aminé, l'autre étant un acide aminé hydrophobe) étaient distantes de 3 à 5 A. Ces unités correspondent parfaite- ment aux unités $\mathrm{AH}-\mathrm{X}$ de l'aspartame. Kouge et al (1988) ont estimé à $4,1 \AA$ A la distance moyenne entre les deux sites nécessaires à la formation d'amertume pour les dipeptides cycliques.

Plus récemment, des chercheurs japonais (Shinoda et al, 1985, 1986a et b) ont montré, en synthétisant des peptides amers et des analogues, que la nature des acides aminés terminaux et leurs paramètres stériques ont une certaine importance quant à l'intensité de l'amertume. Ce point sera illustré par des exemples dans le paragraphe suivant.

\section{Exemples de peptides amers}

Ishibashi et son équipe ont étudié un certain nombre de peptides synthétiques afin de mieux comprendre le mécanisme de l'amertume. Ainsi, suite aux résultats de Fujimaki et al (1968) qui avaient isolé des peptides riches en leucine d'un hydrolysat de protéines de soja, Ishibashi et al (1987a) ont étudié l'importance du résidu leucine dans l'amertume des peptides. Ils ont pu montrer qu'une leucine en C-terminal intensifiait l'amertume. De plus, l'étude des diastéréo-isomères du peptide Leu-Leu a montré qu'ils étaient tous amers bien que la D-Leu soit sucrée (tableau VI).

Matoba et al (1970) ont identifié trois peptides, très amers en solution à $1 \%$. $\mathrm{BPI}$ : Gly-Pro-Phe-Pro-Val-lle, BPII : Phe-PheVal-Ala-Pro-Phe-Pro-Glu-Val-Phe-Gly-Ly s, et BPIII : Phe-Ala-Leu-Pro-Gin-Tyr-LeuLys, ont été isolés d'un hydrolysat trypsique de caséine. Minamiura et al (1972a) ont également identifié deux peptides amers de la caséine: BPla, Arg-Gly-ProPro-Phe-lle-Val et BPIc, Val-Tyr-Pro-PhePro-Pro-Gly-Ile-Asn-His. La richesse de ces peptides en proline, phénylalanine et tyrosine a attiré l'attention de Ishibashi et de ses collaborateurs. Ils ont donc étudié de façon systématique (1987b, 1988a) les peptides riches en Phe et Tyr (tableau VII) ainsi que les peptides riches en Pro (tableau VIII). Comme pour la leucine, la 
Tableau VI. Goût des peptides contenant de la leucine d'après Ishibashi et al, 1987a. Taste of peptides containing leucine from Ishibashi et al, 1987a.

\begin{tabular}{|c|c|c|c|}
\hline Composé & Goût & Seuil (mmol/L) & Rcaf \\
\hline L-Leu & Amer & 20 & 0,05 \\
\hline L-Leu-Na & Amer & 25 & 0,04 \\
\hline D-Leu & Sucré & 6,0 & - \\
\hline DL-Leu & Sucré / Amer & 19,0 & - \\
\hline L-Leu-OMe $\mathrm{HCl}$ & Amer / Acide & 3,1 & - \\
\hline Leu-Leu & Amer & 2,5 & 0,4 \\
\hline Leu-Leu-Leu & Amer & 1,2 & 0,83 \\
\hline Leu-Leu-Leu-Leu & Amer & 0,6 & 1,7 \\
\hline Leu-Leu-Leu-Leu-Leu & Insoluble dans l'eau & & \\
\hline Leu-Leu-Leu-Leu-Leu-Leu & Insoluble dans l'eau & & \\
\hline L-Leu-L-Leu & Amer & 2,5 & 0,4 \\
\hline D-Leu-D-Leu & Amer & 2,5 & 0,4 \\
\hline L-Leu-D-Leu & Amer & 2,5 & 0,4 \\
\hline D-Leu-L-Leu & Amer & 2,5 & 0,4 \\
\hline Gly-L-Leu & Amer & 25 & 0,04 \\
\hline Gly-D-Leu & Amer & 25 & 0,04 \\
\hline L-Leu-Gly & Amer & 20 & 0,05 \\
\hline D-Leu-Gly & Amer & 20 & 0,05 \\
\hline Gly & Sucré & - & - \\
\hline Gly-Gly & Plat & - & - \\
\hline Leu-Gly & Amer & 20 & 0,05 \\
\hline Gly-Leu & Amer & 25 & 0,04 \\
\hline Gly-Gly-Gly & Plat & - & - \\
\hline Leu-Gly-Gly & Amer & 75 & 0,01 \\
\hline Gly-Leu-Gly & Amer & 10 & 0,1 \\
\hline Gly-Gly-Leu & Amer & 10 & 0,1 \\
\hline Leu-Leu-Gly & Amer & 5 & 0,2 \\
\hline Leu-Gly-Leu & Amer & 5 & 0,2 \\
\hline Gly-Leu-Leu & Amer & 1,5 & 0,67 \\
\hline Leu-Gly-Gly-Gly & Amer & 13 & 0,08 \\
\hline Gly-Leu-Gly-Gly & Amer & 19 & 0,05 \\
\hline Gly-Gly-Leu-Gly & Amer & 25 & 0,04 \\
\hline Gly-Gly-Gly-Leu & Amer & 4,5 & 0,22 \\
\hline Leu-Gly-Gly-Gly-Gly & Amer & 13 & 0,08 \\
\hline Gly-Leu-Gly-Gly-Gly & Amer & 13 & 0,08 \\
\hline Gly-Gly-Leu-Gly-Gly & Amer & 13 & 0,08 \\
\hline Gly-Gly-Gly-Leu-Gly & Amer & 13 & 0,08 \\
\hline Gly-Gly-Gly-Gly-Leu & Amer & 2,2 & 0,45 \\
\hline Leu-Asp $\mathrm{HCl}$ & Acide & 3,0 & - \\
\hline Leu-Glu- $\mathrm{HCl}$ & Acide & 1,5 & - \\
\hline Leu-Val & Amer & 6,0 & 0,17 \\
\hline Leu-lle & Amer & 4,0 & 0,25 \\
\hline Leu-Phe & Amer & 1,2 & 0,83 \\
\hline Asp-Leu $\mathrm{HCl}$ & Acide & 0,8 & - \\
\hline Glu-Leu HCl & Acide & 1,5 & - \\
\hline Val-Leu & Amer & 6,0 & 0,17 \\
\hline Ile-Leu & Amer & 1,5 & 0,67 \\
\hline Phe-Leu & Amer & 1,2 & 0,83 \\
\hline
\end{tabular}


Tableau VII. Goût des peptides contenant de la phénylalanine et/ou de la tyrosine d'après Ishibashi et al, 1987b.

Taste of peptides containing phenylalanine and/or tyrosine from Ishibashi et al, 1987b.

\begin{tabular}{|c|c|c|c|}
\hline Composé & Goût & Seuil (mmol/L) & Rcaf \\
\hline L-Phe & Amer & 20 & 0,05 \\
\hline D-Phe & Sucré & 2,2 & - \\
\hline DL-Phe & Sucré / amer & 9,5 & - \\
\hline L-Phe-OMe HCl & Amer & 6,25 & 0,16 \\
\hline L-Phe-L-Phe & Amer & 1,2 & 0,83 \\
\hline D-Phe-D-Phe & Amer & 1,2 & 0,83 \\
\hline L-Phe-D-Phe & Amer & 1,2 & 0,83 \\
\hline D-Phe-L-Phe & Amer & 1,2 & 0,83 \\
\hline L-Phe-Gly & Amer & 6 & 0,17 \\
\hline D-Phe-Gly & Amer & 9 & 0,11 \\
\hline DL-Phe-Gly & Amer & 13 & 0,08 \\
\hline Gly-L-Phe-OMe & Amer & 3,3 & 0,3 \\
\hline Gly-D-Phe-OMe & Amer & 3,1 & 0,32 \\
\hline L-Ala-L-Phe-OMe & Amer & 1,2 & 0,8 \\
\hline L-Ala-D-Phe-OMe & Amer & 1,4 & 0,7 \\
\hline Phe-Gly & Amer & 6,0 & 0,17 \\
\hline Phe-Val & Amer & 6,0 & 0,17 \\
\hline Phe-Leu & Amer & 1,5 & 0,67 \\
\hline Phe-Ile & Amer & 1,5 & 0,67 \\
\hline Phe-lle-Val & Amer & 1,5 & 0,67 \\
\hline Phe-Pro & Amer & 1,5 & 0,67 \\
\hline Phe-Pro-Pro & Amer & 4,5 & 0,22 \\
\hline Phe-Pro-Lys & Amer & 3,0 & 0,33 \\
\hline Phe-Pro-Phe & Amer & 0,4 & 2,5 \\
\hline Phe-Phe-Pro-Pro & Amer & 3,0 & 0,33 \\
\hline Gly-Phe & Amer & 1,2 & 0,83 \\
\hline Ala-Phe & Amer & 12,5 & 0,08 \\
\hline Val-Phe & Amer & 3,0 & 0,33 \\
\hline Leu-Phe & Amer & 1,3 & 0,77 \\
\hline Ile-Phe & Amer & 1,5 & 0,67 \\
\hline Pro-Phe & Amer & 38 & 0,03 \\
\hline Ser-Phe & Umami & 9,0 & - \\
\hline Thr-Phe & Astringent & 2,3 & 一 \\
\hline Lys-Phe & Amer / Sucré & $9,0 / 4,5$ & 0,11 \\
\hline Arg-Phe & Amer & 2,3 & 0,43 \\
\hline Asp-Phe & Acide & - & - \\
\hline Glu-Phe & Acide & - & 一 \\
\hline Val-Ile-Phe & Amer & 1,3 & 0,77 \\
\hline Arg-Pro-Phe & Amer & 1,5 & 0,67 \\
\hline Pro-Pro-Phe & Amer & 2,3 & 0,43 \\
\hline Phe-Pro-Phe & Amer & 0,4 & 2,5 \\
\hline Arg-Pro-Phe-Phe & Amer & 0,04 & 25 \\
\hline Arg-Arg-Pro-Phe-Phe & Amer & 0,02 & 50 \\
\hline Phe-Gly-Gly & Amer & 4,5 & 0,22 \\
\hline Gly-Phe-Gly & Amer & 3,0 & 0,33 \\
\hline Gly-Gly-Phe & Amer & 1,5 & 0,67 \\
\hline Phe-Phe-Gly & Amer & 2,2 & 0,45 \\
\hline
\end{tabular}


Tableau VII. (suite)

\begin{tabular}{lccc}
\hline Composé & Goût & Seuil (mmol/L) & Rcaf \\
\hline Phe-Gly-Phe & Amer & 1,2 & 0,83 \\
Gly-Phe-Phe & Amer & 0,6 & 1,60 \\
Phe-Phe-Phe & Amer & 0,2 & 5,0 \\
Tyr-Gly & Amer & 3 & 0,33 \\
Gly-Tyr & Amer & 3,0 & 0,33 \\
Tyr-Tyr & Amer & 2,3 & 0,43 \\
Tyr-Gly-Gly & Amer & 2,3 & 0,43 \\
Gly-Tyr-Gly & Amer & 19 & 0,05 \\
Gly-Gly-Tyr & Amer & 1,5 & 0,67 \\
Tyr-Tyr-Gly & Amer & 0,6 & 1,60 \\
Tyr-Gly-Tyr & Amer & 0,8 & 1,25 \\
Gly-Tyr-Tyr & Amer & 0,4 & 2,5 \\
Tyr-Tyr-Tyr & Amer & 0,2 & 5,0 \\
Val-Tyr-Pro-Phe-Pro- & Amer & 0,05 & 20 \\
Pro-Gly-lle-Asn-His & & & \\
(BPIc) & & & \\
Val-Tyr & Amer & 3,0 & 0,33 \\
Val-Tyr-Pro & Amer & 3,0 & 0,33 \\
Val-Tyr-Pro-Phe & Amer & 0,3 & 3,3 \\
Tyr-Pro & Amer & 19 & 0,05 \\
Tyr-Pro-Phe & Amer & 0,3 & 3,3 \\
Pro-Phe-Pro & Amer & 0,4 & 2,5 \\
Pro-Phe-Pro-Pro & Amer & 4,5 & 0,22 \\
\hline
\end{tabular}

position en C-terminal de Phe et Tyr provoque une augmentation de l'amertume. Celle-ci est intensifiée par la formation de di- et tri-mères de ces résidus. Les auteurs ont également étudié l'amertume des fragments $\mathrm{N}$-terminaux de BPIc (tableau VII). Ces fragments sont amers mais peu intenses. II semblerait que la structure tertiaire du peptide intervienne dans le mécanisme de l'amertume.

L'étude du résidu proline (Ishibashi et al, 1988a) a montré que si l'hydrophobicité de la proline est un caractère important pour l'amertume, la conformation de la molécule intervient également, favorisant ou non les interactions avec les récepteurs. Les auteurs ont montré que Phe-Pro a un seuil de détection beaucoup plus bas $(1,5 \mathrm{mmol} / \mathrm{L})$ que Pro-Phe $(38 \mathrm{mmol} / \mathrm{L})$. Ils ont montré également que la disposition des cycles dans Tyr-Pro-Phe, Phe-Pro-Phe et Pro-
Phe-Pro était très favorable à l'amertume. Dans un peptide contenant Pro et un acide aminé basique, l'amertume est intensifiée par la proximité de ces deux résidus. Ainsi, Arg-Pro-Gly est amer comme Gly-Arg-Pro mais Arg-Gly-Pro a un seuil de détection très élevé (tableau VIII).

Ce résultat avait été mis en évidence par Otagiri et al (1985) qui ont montré également que, dans un di- ou tripeptide, l'acide aminé hydrophobe doit se trouver en $\mathrm{N}$-terminal pour augmenter l'amertume. Ces différents résultats ont mené à la synthèse d'un peptide Arg-Arg-Pro-Pro-Pro-PhePhe-Phe qui atteint un seuil de $0,002 \mathrm{mmol} / \mathrm{L}$; c'est actuellement le peptide le plus amer connu (Shinoda et al, 1986b) (tableau IX).

Minamiura et al (1972b) ont isolé deux peptides amers d'un hydrolysat de caséine. L'un d'eux, cyclique, a été identifié 
Tableau VIII. Goût des peptides contenant de la proline et/ou de l'arginine d'après Ishibashi et al, 1988a.

Taste of peptides containing proline and/or arginine from Ishibashi et al, 1988a.

\begin{tabular}{|c|c|c|c|}
\hline Peptide & Goût & $\begin{array}{c}\text { Seuil } \\
(\mathrm{mmol} / \mathrm{L})\end{array}$ & Rcat \\
\hline Pro & Sucré / Amer & 13 & 0,08 \\
\hline Pro-Pro & Amer & 4,5 & 0,22 \\
\hline Pro-Pro-Pro & Amer & 2,0 & 0,5 \\
\hline Pro-Gly & Fade & - & - \\
\hline Gly-Pro & Amer & 6 & 0,17 \\
\hline Pro-Pro-Gly & Amer & 9,5 & 0,11 \\
\hline Pro-Gly-Gly & Amer & 4,5 & 0,22 \\
\hline Pro-Gly-Pro & Amer & 9,5 & 0,11 \\
\hline Gly-Pro-Gly & Amer & 20 & 0,05 \\
\hline Gly-Gly-Pro & Amer & 9,5 & 0,11 \\
\hline Pro-Gly-Ile & Amer & 2,3 & 0,43 \\
\hline Pro-Phe-Pro & Amer & 0,4 & 2,5 \\
\hline Pro-Phe-Pro-Pro & Amer & 4,5 & 0,22 \\
\hline Gly-Pro-Pro-Phe & Amer & 3,0 & 0,33 \\
\hline Orn-Pro & Amer & 1,2 & 0,83 \\
\hline Lys-Pro & Amer & 3 & 0,33 \\
\hline Pro-Lys & Amer & 6 & 0,17 \\
\hline Lys-Pro-Lys & Amer & 3 & 0,33 \\
\hline Lys-Pro-Phe & Amer & 0,4 & 2,5 \\
\hline Phe-Pro-Lys & Amer & 3 & 0,33 \\
\hline Arg & Amer & 25 & 0,04 \\
\hline Arg-Arg & Amer & 8 & 0,13 \\
\hline Arg-Arg-Arg & Amer & 4 & 0,25 \\
\hline Arg-Gly & Amer & 10 & 0,1 \\
\hline Gly-Arg & Amer & 100 & 0,01 \\
\hline Arg-Pro & Amer & 0,8 & 1,25 \\
\hline Pro-Arg & Amer & 3 & 0,33 \\
\hline Arg-Gly-Pro & Amer & 13 & 0,08 \\
\hline Pro-Gly-Arg & Amer & 25 & 0,04 \\
\hline Arg-Pro-Gly & Amer & 0,8 & 1,25 \\
\hline Gly-Arg-Pro & Amer & 0,8 & 1,25 \\
\hline
\end{tabular}

comme Cyclo (Leu-Trp-Leu-Trp). Shiba et Nunami (1974) ont montré qu'il s'agit en fait d'une dicétopipérazine Cyclo (Leu-Trp). Ishibashi et al (1988b) ont montré que les peptides cycliques sont en général amers et ont une intensité plus élevée que leurs correspondants linéaires (tableau $\mathrm{X}$ ). Siemon et al (1979) ont également montré que l'intensité de l'amertume dépend de la configuration de la molécule. L'intensité des peptides contenant des acides aminés de configuration L' est nettement supérieure à celle des peptides contenant des acides aminés de configuration $\mathrm{D}$ :

Shinoda et al (1987) ont montré que l'on pouvait faire disparaître l'amertume du dipeptide Arg-Pro en introduisant Gly-Gly en $\mathrm{N}$ - ou C-terminal (tableau IX). L'introduction d'une seule glycine ne provoque pas le même résultat. Ishibashi et al (1988c) ont 
Tableau IX. Comparaison des seuils de détection de peptides amers de composition proche, mais de séquences différentes d'après Otagiri et al, 1985 et Shinoda et al, 1987.

Comparison of threshold values of bitter peptides with the same composition but different sequences from Otagiri et al, 1985 and Shinoda et al, 1987.

\begin{tabular}{|c|c|c|c|}
\hline Composé & $\begin{array}{c}\text { Seuil } \\
(\mathrm{mmol} / \mathrm{L})\end{array}$ & Composé & $\begin{array}{c}\text { Seuil } \\
(\mathrm{mmol} / \mathrm{L})\end{array}$ \\
\hline Phe-Phe & 1,2 & & \\
\hline Gly-Gly-Phe-Phe & 1,4 & $\begin{array}{l}\text { Phe-Phe-Gly-Gly } \\
\text { Gly-Gly-Phe-Phe-Gly-Gly }\end{array}$ & $\begin{array}{l}3,0 \\
0,2\end{array}$ \\
\hline Val-Val-Val & 4,5 & & \\
\hline Gly-Gly-Val-Val-Val & 8,0 & Val-Val-Val-Gly-Gly & - \\
\hline Arg-Pro & 0,8 & & \\
\hline Gly-Arg-Pro & 0,8 & $\begin{array}{l}\text { Arg-Pro-Gly } \\
\text { Gly-Gly-Arg-Pro-Arg-Pro-Gly-Gly }\end{array}$ & $\underline{0,8}$ \\
\hline \multirow[t]{2}{*}{ Arg-Pro-Phe-Phe } & $\begin{array}{l}2,0 \\
0,04\end{array}$ & Arg-Arg-Pro-Pro-Gly-Gly & - \\
\hline & & $\begin{array}{l}\text { Gly-Gly-Arg-Pro-Phe-Phe } \\
\text { Arg-Pro-Phe-Phe-Gly-Gly } \\
\text { Gly-Gly-Arg-Pro-Phe-Phe-Gly-Gly }\end{array}$ & $\begin{array}{l}0,09 \\
0,12 \\
0,04\end{array}$ \\
\hline Phe-Phe-Pro-Gly & 1,25 & Phe-Phe-Pro-Glu & 1,75 \\
\hline \multirow[t]{2}{*}{ Phe-Phe-Pro-Gly-Gly } & 1,5 & Phe-Phe-Glu-Glu & - \\
\hline & & Arg-Pro-Phe-Phe & 0,04 \\
\hline Caféine & 1,0 & Arg-Arg-Pro-Phe-Phe & 0,02 \\
\hline Phénylthiourée & 0,025 & Arg-Arg-Pro-Pro-Phe-Phe & 0,007 \\
\hline Strychnine & 0,003 & Arg-Pro-Pro-Pro-Phe-Phe-Phe & 0,02 \\
\hline Brucine & 0,0008 & Arg-Arg-Pro-Pro-Pro-Phe-Phe-Phe & 0,002 \\
\hline
\end{tabular}

montré que la longueur de la chaîne carbonée du résidu hydrophobe est très importante dans le mécanisme de l'amertume.

\section{Les peptides salés}

Il a été rapporté qu'il peut y avoir un stimulus salé chez les peptides. Ainsi, Tada et al (1984), en recherchant une relation entre la séquence d'un peptide et son amertume, ont obtenu des peptides Orn-Gly/HCl et Lys-Gly/ $\mathrm{HCl}$ ayant un goût « umami » et légèrement salé. Ils ont alors synthétisé des analogues pour étudier le goût salé. Parmi ces peptides Orn- $\beta \mathrm{Ala} / \mathrm{HCl}$, Orn- $\gamma \mathrm{Abu} / \mathrm{HCl}$, Orn-Tau/HCl, Lys-Tau/ $\mathrm{HCl}$ avaient un goût salé. $\mathrm{A}_{2} \mathrm{Bu}-\gamma \mathrm{Abu} / \mathrm{HCl}$, Orn-Gly/HCl, LysGly $/ \mathrm{HCl}, \mathrm{A}_{2} \mathrm{Bu}-\mathrm{Tau} / \mathrm{HCl}$, avaient également un arrière-goût salé $\left(A_{2} B u\right.$ : acide diamino butyrique).

Huynh-Ba et Philippossian (1990) ont mis en doute ces résultats : d'après eux, le goût salé ne vient pas du peptide mais de la présence d'ions sodium, provenant de la synthèse, dans le milieu.

La réponse de Tamura et Okai (1990) et l'article de Séki et al (1990) semblent pourtant bien justifier ces résultats. Ce dernier a synthétisé deux peptides salés : Orn$\beta \mathrm{Ala} / 1,3 \mathrm{HCl}$ et $\mathrm{Orn}-\beta \mathrm{AlaOMe} / 2 \mathrm{HCl}$, dont le seuil de perception est, respectivement, 1,57 et $2,2 \mathrm{mmol} / \mathrm{L}$ pour la saveur salée 
Tableau X. Goût des peptides linéaires et cycliques : comparaison d'après Ishibashi et al, 1988b. Comparison of the taste from linear peptides and the corresponding cyclic peptides from Ishibashi et al, $1988 b$.

\begin{tabular}{|c|c|c|c|c|c|}
\hline Peptide cyclique & Goût & $\begin{array}{l}\text { Seuil } \\
\text { (mmol/L) }\end{array}$ & $\begin{array}{l}\text { Peptide } \\
\text { linéaire }\end{array}$ & Goût & $\begin{array}{l}\text { Seuil } \\
\text { (mmol/L) }\end{array}$ \\
\hline Cyclo (Gly-Gly) & Fade & - & Gly-Gly & Fade & - \\
\hline Cyclo (Ala-Ala) & Fade & - & Ala-Ala & Fade & - \\
\hline \multirow[t]{2}{*}{ Cyclo (Ala-Gly) } & Fade & - & Ala-Gly & Fade & - \\
\hline & & & Gly-Ala & Fade & - \\
\hline Cyclo (Val-Val) & Amer & 5 & Val-Val & Umami & \\
\hline \multirow[t]{2}{*}{ Cyclo (Val-Gly) } & Amer & 5 & Val-Gly & Umami & \\
\hline & & & Gly-Val & Amer & 4,5 \\
\hline Cyclo (Leu-Leu) & Amer & 1,2 & Leu-Leu & Amer & 2,5 \\
\hline \multirow[t]{2}{*}{ Cyclo (Leu-Gly) } & Amer & 2 & Leu-Gly & Amer & 20 \\
\hline & & & Gly-leu & Amer & 25 \\
\hline Cyclo (Ile-Ile) & Amer & 0,6 & lle-lle & Amer & 1,5 \\
\hline \multirow[t]{2}{*}{ Cyclo (Ile-Gly) } & Amer & 1,2 & Ile-Gly & Amer & 4,5 \\
\hline & & & Gly-lle & Amer & 2,5 \\
\hline Cyclo (Phe-Phe) & Insoluble & & Phe-Phe & Amer & 1,2 \\
\hline \multirow[t]{2}{*}{ Cyclo (Phe-Gly) } & Amer & 1,0 & Phe-Gly & Amer & 6 \\
\hline & & & Gly-Phe & Amer & 1,2 \\
\hline Cyclo (Orn-Orn) & Umami & & Orn-Orn & Fade & - \\
\hline \multirow[t]{2}{*}{ Cyclo (Orn-Gly) } & Umami & & Orn-Gly & Umami & \\
\hline & & & Gly-Orn & Umami & \\
\hline Cyclo (Lys-Lys) & Umami & & Lys-Lys & Fade & - \\
\hline \multirow{2}{*}{ Cyclo (Lys-Gly) } & Amer & 5 & Lys-Gly & Umami & \\
\hline & & & Glys-Lys & Umami & \\
\hline Cyclo (Arg-Arg) & Amer & 0,75 & Arg-Arg & Amer & 9,5 \\
\hline \multirow[t]{2}{*}{ Cyclo (Arg-Gly) } & Amer & 5 & Arg-Gly & Amer & 9,5 \\
\hline & & & Gly-Arg & Amer & 75 \\
\hline \multirow[t]{2}{*}{ Cyclo (Asp-Gly) } & Acide & & Asp-Gly & Acide & \\
\hline & & & Gly-Asp & Acide & \\
\hline Cyclo (Glu-Gly) & Acide & & Glu-Gly & Acide & \\
\hline Cyclo (Pro-Pro) & Fade & - & Pro-Pro & Amer & 4,5 \\
\hline Cyclo (Arg-Phe) & Amer & 0,45 & Arg-Phe & Amer & 2,3 \\
\hline \multirow[t]{2}{*}{ Cyclo (Arg-Pro) } & Amer & 0,45 & Arg-Pro & Amer & 0,8 \\
\hline & & & Pro-Arg & Amer & 3 \\
\hline Cyclo (His-Phe) & Amer & 0,5 & & & \\
\hline
\end{tabular}

mais qui sont également légèrement acides. D'après les auteurs, il n'y a pas de sels dans les échantillons purifiés.

II semblerait, d'après cette étude, que le goût salé soit dépendant de la longueur des chaînes carbonées des acides aminés constituant le dipeptide. En effet, si l'on considère un dipeptide :

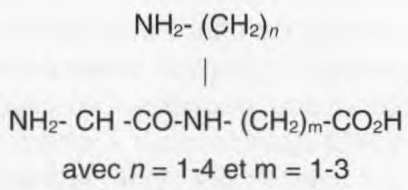

on obtient une saveur salée pour $n=3$ quelle que soit la valeur de $m$ et pour $n=4$, $\mathrm{m}=1$ (peptide Lys-Gly). 
Tableau XI. Quelques peptides acides de la littérature (acides aminés de configuration L ; a : accompagné d'amertume et d'astringence ; $b$ : accompagné d'astringence) d'après Kato et al, 1989. Sour peptides; all amino acids have the L-configuration; a, accompanied by bitterness and astringency; $b$, accompanied by astringency; from Kato et al, 1989.

\begin{tabular}{llll}
\hline Gly-Asp & Val-Asp & Glu-Glu & Trp-Glu \\
Gly-Glu & Val-Glu & Glu-Phe $^{a}$ & $\gamma$-Glu-Gly \\
Ala-Asp & Asp-Ala & Glu-Tyr & $\gamma$-Glu-Ala \\
Ala-Glu & Asp-Asp & Phe-Asp & $\gamma$-Glu-Asp \\
Ser-Asp & Glu-Ala & Phe-Glu & $\gamma$-Glu-Gly \\
Ser-Glu & Glu-Asp & Trp-Asp & \\
Gly-Asp-Ser-Gly & Pro-Gly-Gly-Glu & Val-Val-Glu & \\
& & & \\
\hline
\end{tabular}

II semblerait qu'il y ait un lien entre le goût salé et le goût " umami " comme entre le sucré et l'amer. En effet, Tamura et al (1989) ont obtenu à partir de dipeptides acides (Asp-Asp, Asp-Glu, Glu-Asp, Glu-Glu) des stimulations simultanées de type "umami " et salé en présence d'ions sodium.

Comme les peptides sucrés, les peptides salés présentent un intérêt non négligeable en nutrition pour les personnes souffrant d'hypertension.

\section{Les peptides acides}

De nombreux peptides contenant en général Asp ou Glu ont été reconnus acides (tableau XI). Cette propriété peut être due à l'interaction du proton, obtenu par dissociation de l'acide aminé acide du peptide, avec la membrane des cellules du goût. D'après Kirimura et al (1969) un dipeptide acide doit contenir soit deux acides aminés acides, soit un acide aminé acide et un neutre, ou encore un acide aminé acide et un aromatique.

\section{Les peptides " umami »}

De nombreux dipeptides ayant un L-Glu en $\mathrm{N}$-terminal ont un goût "umami ", mais leur intensité est, en général, bien inférieure à celle du MSG.

Arai et al (1973) ont synthétisé 12 dipeptides possédant un Glu en $\mathrm{N}$-terminal et ont examiné leurs goûts en solution aqueuse à $1 \%$ et à pH 6 : Glu-Asp, Glu-Thr, Glu-Ser,
Glu-Glu étaient " umami » tandis que les autres étaient amers (Glu-lle, Glu-Leu, Glu-Tyr, Glu-Phe) ou n'avaient pas de goût (Glu-Gly, Glu-Ala, Glu-Pro, Glu-Val). Les auteurs ont remarqué que les peptides « $u$ mami " étaient plus acides, plus polaires et hydrophiles que les autres. Un test identique sur un tripeptide " umami ", Glu-GlySer, a montré qu'il possédait les mêmes propriétés. De plus, une O-acétylation de la sérine provoque une baisse de l'hydrophilicité et une disparition simultanée du goût. Une O-butyrylation provoque une augmentation de l'hydrophobicité et une transformation de la saveur " umami " en amertume.

Ohyama et al (1988) ont synthétisé des di- et tripeptides contenant Asp et Glu. La plupart des dipeptides étudiés sont, à la fois, amers et « umami ". Les tripeptides, contenant en $\mathrm{N}$-terminal un acide aminé acide lié par ses deux fonctions acides à deux autres acides aminés, se sont révélés pour la plupart " umami ". Les seuils de détection sont comparables à ceux du MSG, et Glu (Ala) 2 a même un seuil deux fois plus faible que celui du MSG (tableau XII).

Fujimaki et al (1973) ont isolé une fraction peptidique, ayant une flaveur acide et " umami ", d'un hydrolysat de protéines de poisson. La détermination des acides aminés $\mathrm{N}$ et $\mathrm{C}$-terminaux a révélé une grande proportion de Asp et Glu. Noguchi et al 
Tableau XII. Goût des peptides contenant l'acide aspartique et/ou l'acide glutamique (Ohyama et al, 1988). Taste of peptides containing aspartic acid and/or glutamic acid (Ohyama et al, 1988).

\begin{tabular}{lcccc}
\hline & & \multicolumn{2}{c}{ Seuil (mmol/L) } \\
Peptides & Goût & Amer & Umami & Rcaf \\
\hline Gly-Asp & Umami & - & 6 & - \\
Ala-Asp & Amer / Umami & 6 & 13 & 0,17 \\
Val-Asp & Amer / Umami & 13 & 25 & 0,08 \\
Leu-Asp & Amer & 6 & - & 0,17 \\
Gly-Glu & Amer / Umami & 1,5 & 0,8 & 0,67 \\
Ala-Glu & Umami & - & 1,5 & - \\
Val-Glu & Amer / Umami & 6 & 1,5 & 0,17 \\
Leu-Glu & Amer / Umami & 3 & 1,5 &,- 33 \\
Asp (Gly) 2 & Umami & - & 1,5 & - \\
Asp (Ala) 2 & Amer / Umami & 13 & 3 & - \\
Asp (Val) 2 & Umami & - & 13 & - \\
Asp-Leu & Umami & - & 2,5 &,- 25 \\
Asp (Leu) 2 & Amer / Umami & 0,8 & - & - \\
Glu (Gly) 2 & Amer / Umami & 1,5 & 1,5 & - \\
Glu (Ala) 2 & Umami & - & 0,8 & - \\
Glu-(Val)2 & Umami & - & 1,5 & - \\
Glu-Leu & Umami & - & 3 & - \\
Glu (Leu) 2 & Amer & 0,4 & - & \\
MSG & Umami & - & 1,5 & \\
\hline
\end{tabular}

(1975a) ont isolé des peptides du même type en hydrolysant des protéines de poisson par la pronase. Parmi les peptides identifiés, les peptides « umami » sont caractérisés par la présence de Glu et d'un certain nombre d'acides aminés hydrophiles. Ainsi, quatre dipeptides : Glu-Asp, Glu-Glu, Glu-Ser, Thr-Glu et cinq tripeptides : Asp-Glu-Ser, Glu-Asp-Glu, Glu-GinGlu, Glu-Gly-Ser et Ser-Glu-Glu ont été isolés. Ils ont un goût très proche de celui du MSG mais leurs seuils de détection sont à peu près dix fois supérieurs au seuil du MSG.

En 1978, un peptide dit « délicieux " a été isolé d'un extrait de bœuf hydrolysé par la papaïne (Yamasaki et Maekawa, 1978). Sa structure a été confirmée par Yamasaki et Maekawa (1980). II s'agit d'un octapeptide dont la séquence est la suivante : Lys-GlyAsp-Glu-Glu-Ser-Leu-Ala. Les auteurs ont pu montrer, en travaillant sur des fragments de ce peptide (tableau XIII), que l'extrémité
C-terminale était amère mais que son élongation provoquait une diminution de l'amertume et l'apparition d'acidité. L'élongation par Lys-Gly en N-terminal réduit l'acidité et fait disparaître l'astringence. Globalement, ce peptide a un véritable goût de viande. Tamura et al (1989) ont montré que ce goût peut être obtenu avec la même intensité avec les mélanges suivants :

Lys-Gly + Asp-Glu-Glu + Ser-Leu-Ala (seuil : 1,41 $\mathrm{mmol} / \mathrm{L}$ )

Orn- $\beta$ Ala + Asp-Glu-Glu + Ser-Leu-Ala (seuil : $1,41 \mathrm{mmol} / \mathrm{L}$ )

Un seuil encore plus faible est obtenu avec le mélange :

Lys-Glu + Glu-Glu + Ser-Leu-Ala (seuil : $0,94 \mathrm{mmol} / \mathrm{L}$ )

Ces résultats montrent que le goût du peptide délicieux est produit par l'effet combiné du dipeptide basique $\mathrm{N}$-terminal et du peptide acide central. II semblerait que les fonctions anioniques et cationiques du 
peptide stimulent les récepteurs du goût pour obtenir la saveur " umami ".

Noguchi et al (1975b) ont montré qu'une fraction contenant des peptides riches en acide glutamique avait un effet masquant vis-à-vis de l'amertume. À partir de protéines de poisson hydrolysées par la pronase, ils ont tout d'abord obtenu une fraction très amère. Cette fraction a été alors mélangée à une quantité importante d'acide glutamique, puis transformée en plastéine par une endopeptidase puis hydrolysée à nouveau par la pronase. L'hydrolysat ainsi obtenu a un léger goût de bouillon et ne présente aucune amertume. Ce goût se retrouve de façon plus nette dans la fraction ne contenant que les composés de basse masse moléculaire. Cette fraction est constituée de composés acides ayant un goût de bouillon et de composés neutres et basiques amers. L'activité de la fraction acide et du dipeptide Glu-Glu a été vérifiée sur des substances amères: Ile, Ile-Leu, et divers produits tels que la caféine et la brucine. Les résultats obtenus, en ce qui concerne la disparition de l'amertume, sont excellents.

\section{LE GOÛT DES PROTÉINES}

II est généralement admis que les protéines n'ont pas de goût particulier, mais qu'elles contribuent indirectement à la fla- veur par des sensations tactiles. Cela est particulièrement vrai pour des aliments riches en protéines, tels que le lait, les produits laitiers, ou la viande. II a été également mentionné que ces composés pouvaient contribuer au goût de certaines substances par l'intermédiaire de l'astringence (Solms, 1969). Pourtant, depuis les années 1970 , plusieurs protéines à goût sucré ont été découvertes avec des pouvoirs sucrants pouvant dépasser 3000 fois celui du saccharose, à masse égale.

\section{La monelline}

Le fruit de la plante tropicale Dioscoreophyllum cumminsii Diels a un goût sucré très intense. De plus, cette sensation sucrée persiste en bouche plus longtemps que d'ordinaire.

Morris et Cagnan (1972) ont réussi à isoler le principe sucré de ce fruit. Des expériences préliminaires leur ont permis d'indiquer qu'il s'agissait d'une protéine. Son pouvoir sucrant est estimé environ 3000 fois supérieur à celui du saccharose (en masse). La monelline est la première protéine connue pour sa saveur sucrée.

Les études structurales sur cette protéine ont mené aux résultats suivants (Kohmura et al, 1990a): la monelline est une protéine constituée de deux chaînes polypeptidiques de 44 et 50 résidus. II en existe plu-

Tableau XIII. Goût des fragments de l'octapeptide " délicieux " (Yamasaki et Maekawa, 1980). Evaluation of taste of some peptides related to the octapeptide (Yamasaki and Maekawa, 1980).

\begin{tabular}{|c|c|c|c|c|c|}
\hline $\begin{array}{l}\text { Peptides } \\
(50 \mathrm{mg} / \mathrm{mL})\end{array}$ & Sucré & Acide & Amer & Umami & Astringent \\
\hline Lys-Gly-Asp-Glu-Glu-Ser-Leu-Ala & 10 & 30 & 0 & 60 & 0 \\
\hline Asp-Glu-Glu-Ser-Leu-Ala & 5 & 60 & 2 & 10 & 15 \\
\hline Glu-Glu-Ser-Leu-Ala & 0 & 55 & 5 & 10 & 18 \\
\hline Glu-Ser-Leu-Ala & 0 & 44 & 3 & 5 & 32 \\
\hline Ser-Leu-Ala & 0 & 5 & 55 & 0 & 10 \\
\hline Lys-Glys $\longrightarrow$ Ser-Leu-Ala & 0 & 0 & 50 & 0 & 13 \\
\hline Lys-Gly-Asp & 0 & 0 & 0 & 0 & 0 \\
\hline Lys-Gly & 0 & 0 & 0 & 0 & 5 \\
\hline
\end{tabular}


sieurs variants. Sa masse moléculaire est voisine de $10900 \mathrm{Da}$.

Une étude sur la monelline préparée par synthèse chimique (un seul variant) (Kohmura et al, 1990b) a montré que celle-ci était 4000 fois plus sucrée que le saccharose (130 000 fois sur une base molaire, par rapport à une solution à $0,6 \%$ de saccharose). La chaîne B seule donne également ce résultat.

La production de monelline dans des fruits et des légumes transgéniques afin d'en améliorer les propriétés sensorielles est à l'étude (Penarrubia et al, 1992). Des travaux sont également en cours pour déterminer le site actif de cette protéine (Kohmura et al, 1992, 1994). Déjà, les auteurs ont observé que certains acides aminés de la chaîne $B$ semblent indispensables pour produire le goût sucré (lle $6, \mathrm{Asp}_{7}$, $\mathrm{Ile}_{8}$ ). Une forte homologie (> $23 \%$ ) avec les cystatines a également été mise en évidence (Murzin, 1993).

\section{La thaumatine}

Le fruit de la plante tropicale Thaumatococcus daniellii Benth contient une substance très sucrée avec un arrière-goût de réglisse.

Van der Wel et Loeve (1972) ont extrait de ce fruit deux protéines basiques ayant une saveur sucrée et appelées thaumatine I et II. Ces deux protéines font partie d'une famille d'au moins sept molécules ne se différenciant que par la substitution de cinq acides aminés (Witty, 1990). Elle constitue avec la thaumatopaïne (cystéine protéase de la famille de la papaïne associée à la thaumatine sous forme d'un complexe) $99 \%$ des protéines de ce fruit (Stephen et al, 1991). La thaumatine est une protéine contenant 207 acides aminés (tableau XIV) et huit ponts disulfures (McPherson et Weickmann, 1990). Sa masse est d'environ 22 kDa (Thl : 22209 ; Thll : 22 293). La protéine interagit avec les récepteurs humains du goût en produisant une saveur sucrée
Tableau XIV. Composition en acides aminés des protéines sucrées Thaumatine I et II (en $\mathrm{g} / 100 \mathrm{~g}$ de protéine) d'après Van der Wel et Loeve, 1972.

Amino acid composition of the sweet-tasting proteins Thaumatin I and Thaumatin II from Van der Wel and Loeve, 1972.

\begin{tabular}{lcc}
\hline Acide amine & Thaumatine I & Thaumatine II \\
\hline Asp & 11,4 & 10,9 \\
Glu & 6,0 & 6,3 \\
Ser & 4,9 & 4,4 \\
Thr & 9,0 & 8,5 \\
Pro & 5,8 & 5,8 \\
Gly & 6,3 & 6,1 \\
Ala & 5,2 & 5,0 \\
Val & 4,2 & 4,1 \\
Leu & 5,0 & 5,1 \\
lle & 4,0 & 3 \\
Met & 0,6 & 0,8 \\
Phe & 7,3 & 7,2 \\
Tyr & 5,5 & 6,2 \\
Cys & 6,9 & 6,6 \\
His & - & - \\
Lys & 6,4 & 6,6 \\
Arg & 8,5 & 9,4 \\
Trp & 3,1 & 3,1 \\
\hline
\end{tabular}

très intense : une solution à $10^{-8} \mathrm{~mol} / \mathrm{L}$ est sucrée. Son pouvoir sucrant est 3000 fois supérieur à celui d'une solution à $8 \%$ de saccharose ( 100000 supérieur sur la base molaire). À des concentrations plus faibles, la saveur sucrée n'est pas détectable, mais la thaumatine joue alors le rôle d'exhausteur de goût. Ces propriétés, liées au fait que la thaumatine est une molécule non toxique, qu'elle n'intervient pas dans un processus carieux, qu'elle n'apporte que peu de calories $(17 \mathrm{~kJ} / \mathrm{g})$, font de cette molécule un substitut idéal pour les sucres. Toutefois, il faut noter la baisse de son pouvoir sucrant en présence de carraghénanes (Ohashi et al, 1991). Son utilisation est autorisée au Japon, en Grande-Bretagne, en Australie et aux États-Unis pour certaines applications telles que les chewing-gums. 
Plusieurs compagnies américaines ont lancé un projet de recherche pour la production de thaumatine par un procédé biotechnologique, faisant intervenir des levures recombinées (Vincent et Delest, 1990). Une bibliothèque d'anticorps monoclonaux contre la thaumatine a été développée. Elle a permis de mettre en évidence plusieurs épitopes. Certains de ces anticorps interagissent également avec la monelline (Mandal et al, 1991). Il est intéressant de noter que la monelline et la thaumatine ont en commun sept séquences de trois acides aminés qui n'existent pas chez les modificateurs de goût, la curculine et la miraculine. Ces peptides pourraient faire partie du site actif de ces protéines (Kohmura et al, $1992,1994)$. Les connaissances actuelles sur les thaumatines ont fait l'objet d'une revue par Van der Wel et Ledeboer (1989).

\section{La pentadine}

Cette protéine sucrante a été isolée à partir des graines d'un arbuste originaire du Gabon : le Pentadiplandra brazzeana Baillon. Elle contient 108 acides aminés et sa masse moléculaire est $12 \mathrm{kDa}$ environ. Son pouvoir sucrant est 500 fois supérieur à celui du saccharose et son goût est beaucoup moins tenace que celui de la thaumatine (Van der Wel et al, 1989).

\section{La mabinline}

Elle a été mise en évidence dans les graines de Capparis masakai Levl. II s'agit en fait de deux protéines, mabinline l et mabinline II, ayant respectivement une masse de 11600 et $10400 \mathrm{Da}$. Leurs séquences sont très proches et l'intensité de la saveur sucrée se rapproche de celle de la thaumatine. L'une d'elles, la mabinline II, a été purifiée et séquençée par Xiaozhu et al (1993). C'est une protéine thermostable ayant deux sous-unités, $A$ et $B$. La chaîne $A$ (33 acides aminés) est composée princi- palement d'acides aminés hydrophiles et la chaîne $B$ (72 résidus) en contient également une forte proportion.

\section{La miraculine}

La miraculine est une glycoprotéine provenant d'un arbre fruitier africain, le Richardella dulcifica Baehni. En réalité, trois protéines, ayant toutes une masse d'environ 40-41 kDa, ont été extraites de cette plante (Kinghorn et Soejarto, 1989). La miraculine, contrairement aux autres protéines citées, n'est pas une protéine sucrée mais un modificateur de goût. En effet, ce fruit " miracle " a la propriété de modifier le goût des aliments acides, des minéraux dilués, des acides organiques en goût sucré après que la pulpe du fruit ait été mâchée. Cet effet peut ensuite durer 1 à 2 heures (Brouwer et al, 1968). La qualité de la saveur sucrée obtenue par ce modificateur est très proche du saccharose (Sardesai et Waldshan, 1991).

\section{La curculine}

Le fruit de Curculigo latifolia, arbre fruitier malaysien, contient une autre protéine ayant la caractéristique de modifier le goût : la curculine (Yamashita et al, 1990). Cette protéine de 114 résidus est sucrée par elle-même mais se caractérise par sa propriété à transformer l'acidité en goût sucré. Sa séquence est différente de celle de la miraculine et son mode d'action n'a pas encore été élucidé. Toutefois, elle a été clonée et séquencée et sa surproduction chez Escherichia coli ou Saccharomyces cerevisiae est envisagée (Abe et al, 1992).

Pour mémoire, nous avons regroupé dans le tableau XV les édulcorants utilisés à ce jour et dans le tableau XVI les édulcorants à base peptidique en cours de développement. 
Tableau XV. Pouvoir sucrant d'édulcorants naturels et synthétiques (Sardesai et Waldshan, 1991).

Natural and synthetic sweeteners (Sardesai and Waldshan, 1991).

\begin{tabular}{lc}
\hline Édulcorant & $\begin{array}{c}\text { Pouvoir sucrant/ } \\
\text { Saccharose }\end{array}$ \\
\hline Acésulfame K & 200 \\
Alitame & 2000 \\
Aspartame & $160-200$ \\
Cucurbitane & 250 \\
Cyclamate & 30 \\
Fructose & 1,7 \\
Glycyrrhizine & $50-100$ \\
Monelline & $2500-3000$ \\
Néohespéridine & \\
dihydrochalcone & $250-2000$ \\
Néosucre & $0,4-0,6$ \\
Osladine & 3000 \\
Palatinose & 0,4 \\
Périandrines I-IV & $90-100$ \\
Pentadine & 500 \\
Perrillartine & 350 \\
Rebaudioside A & 400 \\
Rubusoside & 114 \\
Saccharine & 300 \\
Sorbitol & 0,5 \\
Stévioside & 300 \\
Sucralose & 500 \\
Saccharose & 1 \\
Suosan & 20000 \\
Thaumatine & $>3000$ \\
Xylitol & 1,7 \\
& \\
&
\end{tabular}

\section{LES PEPTIDES SAPIDES DANS LE FROMAGE ET LES HYDROLYSATS DE CASÉINES}

La caséine, qui est l'une des protéines alimentaires les plus hydrophobes, a tendance à produire de l'amertume lorsqu'elle est hydrolysée. Ce défaut de goût est un problème bien connu en fabrication fromagère et est souvent attribué à la formation de peptides amers (Lowrie et al, 1972 ; Visser, 1977). De nombreux peptides amers ont été mis en évidence lors de la digestion de diverses protéines par des protéases et si l'on regarde la séquence de ces peptides, on remarque une large proportion de résidus hydrophobes.

\section{Identification de peptides amers dans les hydrolysats de caséines}

Dans les années 1970, de nombreux peptides amers ont été décrits dans les hydrolysats de caséines (tableaux XVII, XVIII, $X I X)$. Certains d'entre eux sont cités dans la revue de Guigoz et Solms (1976). Lemieux et Simard $(1991,1992)$ ont également fait le point sur le mécanisme de formation des peptides amers dans les produits laitiers, ainsi que sur leur mode d'action.

Tableau XVI. Édulcorants à base peptidique en cours de développement d'après Teeuwen, 1991. Oligopeptide-based high-intensity sweeteners under development from Teeuwen, 1991.

\begin{tabular}{lcc}
\hline Édulcorant & Inventeur-Fabricant & Pouvoir sucrant \\
\hline $\begin{array}{l}\text { Dérivés de l'aspartame } \\
\text { Dérivés de l'acide Aspartyl }\end{array}$ & Université Claude Bernard & $\leq 55000$ \\
$\begin{array}{lc}\text { aminomalonique } \\
\text { Aspartyl D-alaninol amide ester }\end{array}$ & $\begin{array}{l}\text { Takeda Chemical } \\
\text { Dérivés de l'acide }\end{array}$ & $\leq 33000$ \\
aminodicarboxylique & Tanabe Seiyaku & $\leq 200$ \\
Tripeptides & General Foods & $\leq 1200$ \\
Autres oligopeptides sucrés & Ajinomoto & $\leq 180$ \\
& Ajinomoto & \\
& American home prod \\
Nutrasweet Co & \\
& Procter et Gamble Squib &
\end{tabular}


Tableau XVII. Peptides amers provenant de la dégradation de la caséine $\alpha_{s 1}$. Bitter peptides from $\alpha_{s 1}$ casein degradation

\begin{tabular}{rllc}
\hline$N^{\circ}$ & Position & Séquence & Origine ou obtenu par action de \\
\hline 1 & $14-17$ & Glu-Val-Leu-Asn & Cheddar \\
2 & $17-21$ & Asn-Glu-Asn-Leu-Leu & Cheddar \\
3 & $21-23$ & Leu-Arg-Phe & Présure \\
4 & $23-34$ & Phe-Phe-Val-Ala-Pro-Phe-Pro-Gln-Val-Phe-Gly-Lys & Trypsine, séquençage caséine \\
5 & $29-32$ & Pro-Gln-Val-Phe & Présure \\
6 & $91-100$ & Tyr-Leu-Gly-Tyr-Leu-Glu-Gln-Leu-Leu-Arg & Trypsine \\
7 & $92-99$ & Leu-Gly-Tyr-Leu-Glu-Gln-Leu-Leu & Séquençage caséine \\
8 & $99-101$ & Leu-Arg-Leu & Présure \\
9 & $143-149$ & Ala-Tyr-Phe-Tyr-Pro-Glu-Leu & Présure \\
10 & $145-148$ & Phe-Tyr-Pro-Glu & Chymotrypsine + Thermolysine \\
11 & $145-150$ & Phe-Tyr-Pro-Glu-Leu-Phe & Chymotrypsine \\
12 & $145-151$ & Phe-Tyr-Pro-Glu-Leu-Phe-Arg & Séquençage caséine et Trypsine \\
13 & $149-150$ & Leu-Phe & Chymotrypsine + Thermolysine \\
14 & $167-179$ & Val-Pro-Leu-Gly-Thr-Gln-Tyr-Thr-Asp-Ala-Pro-Ser-Phe & Présure \\
15 & $198-199$ & Leu-Trp & Cyclo (Leu-Trp) \\
16 & $198-199$ & Fromage suisse \\
\hline & & & Protéase $B$ subtilis \\
\hline
\end{tabular}

Minamiura et al $(1972 \mathrm{a}, \mathrm{b})$ ont isolé trois peptides amers obtenus par action d'une protéase alcaline de Bacillus subtilis sur la caséine. Le peptide 36 a une séquence proche de la séquence C-terminale de la caséine $\beta$ (BPla). Les auteurs ont montré que si on libère le résidu Arg $\mathrm{N}$-terminal ou le peptide Ile-Val C-terminal, l'intensité de l'amertume ne varie pas. Toutefois le peptide Pro-Pro-Phe n'est pas amer. Le peptide Gly-Pro-Pro-Phe est donc à l'origine de l'amertume. Le peptide 37 ressemble, à deux inversions près, au peptide 59-68 de la caséine $\beta$ (BPIc). Ce peptide, ainsi que des fragments ont été synthétisés par
Kanehisha (1984). Ainsi, l'auteur a montré que le peptide 38 est 20 fois plus amer que la caféine. Le peptide 39 est un peptide cyclique qui pourrait provenir de la séquence C-terminale de la caséine $\alpha_{s 1}$ (BPII).

En effet, une étude plus poussée de cette molécule a permis à Shiba et Nunami (1974) de montrer qu'il s'agissait en fait d'une dicétopipérazine (16) ayant pour origine l'extrémité C-terminale de la caséine $\alpha_{s 1}$.

Trois peptides ont été isolés d'un hydrolysat trypsique de caséine (Matoba et al, 1970). Le peptide 40 correspond, à un acide aminé près, au fragment 203-208 de la caséine $\beta$ (BPI), le résidu souligné étant 
Tableau XVIII. Peptides amers provenant de la dégradation de la caséine $\beta$.

Bitter peptides from $\beta$ casein degradation.

\begin{tabular}{|c|c|c|c|}
\hline$N^{\circ}$ & Position & Séquence & Origine ou obtenu par action de \\
\hline 17 & $46-67$ & $\begin{array}{l}\text { Gln-Asp-Lys-Ile-His-Pro-Phe-Ala-Gln-Thr-Gin-Ser- } \\
\text { Leu-Val-Tyr-Pro-Phe-Pro-Gly-Pro-Ile-Pro }\end{array}$ & Cheddar \\
\hline 18 & $53-79$ & $\begin{array}{l}\text { Ala-GIn-Thr-Gln-Ser-Leu-Val-Tyr-Pro-Phe-Pro-Gly-Pro- } \\
\text { Ile-Pro-Asn-Ser-Leu-Pro-Gln-Asn-Ile-Pro-Pro-Leu-Thr-Gln }\end{array}$ & Papaïne \\
\hline 19 & $61-67$ & Pro-Phe-Pro-Gly-Pro-lle-Pro & Synthèse \\
\hline 20 & $82-88$ & Val-Val-Val-Pro-Pro-Phe-Leu & Synthèse \\
\hline 21 & $84-89$ & Val-Pro-Pro-Phe-Leu-Gln & Gouda \\
\hline 22 & $103-105$ & Ala-Pro-Lys & Séquençage de caséine \\
\hline 23 & $167-175$ & Gln-Ser-Lys-Val-Leu-Pro-Val-Pro-Glu & Protéase de paroi, L lactis \\
\hline 24 & $176-182$ & Lys-Ala-Val-Pro-Tyr-Pro-Gln & Protéase de paroi, $L$ lactis \\
\hline 25 & $183-193$ & Arg-Asp-Met-Pro-lle-Gln-Ala-Phe-Leu-Leu-Tyr & Protéase de paroi, L lactis \\
\hline 26 & $190-192$ & Phe-Leu-Leu & Présure \\
\hline 27 & $193-207$ & $\begin{array}{l}\text { Tyr-Gin-Gin-Pro-Val-Leu-Gly-Pro-Val-Arg-Gly-Pro-Phe- } \\
\text { Pro-lle-lle }\end{array}$ & Gouda \\
\hline 28 & $193-208$ & $\begin{array}{l}\text { Tyr-Gln-Gln-Pro-Val-Leu-Gly-Pro-Val-Arg-Gly-Pro-Phe- } \\
\text { Pro-Ile }\end{array}$ & Gouda \\
\hline 29 & $193-209$ & $\begin{array}{l}\text { Tyr-Gln-Gin-Pro-Val-Leu-Gly-Pro-Val-Arg-Gly-Pro-Phe- } \\
\text { Pro-Ile-Ile-Val }\end{array}$ & Gouda \\
\hline 30 & $194-207$ & Gln-Gln-Pro-Val-Leu-Gly-Pro-Val-Arg-Gly-Pro-Phe-Pro-Ile & Protéase de paroi, L lactis \\
\hline 31 & 194-209 & $\begin{array}{l}\text { Gln-Gln-Pro-Val-Leu-Gly-Pro-Val-Arg-Gly-Pro-Phe-Pro-Ile } \\
\text {-\|e-Val }\end{array}$ & Protéase de paroi, L lactis \\
\hline 32 & $196-209$ & Pro-Val-Leu-Gly-Pro-Val-Arg-Gly-Pro-Phe-Pro-Ile-Ile-Val & Synthèse \\
\hline 33 & $199-202$ & Gly-Pro-Val-Arg & Vacherin Mont d'Or \\
\hline 34 & $202-209$ & Arg-Gly-Pro-Phe-Pro-lle-lle-Val & Synthèse \\
\hline 35 & 203-209 & Gly-Pro-Phe-Pro-Ile-lle-Val & Séquençage, synthèse \\
\hline
\end{tabular}

une isoleucine dans cette protéine. Le peptide 41 correspond au fragment 23-34 de la caséine $\alpha_{\mathrm{s} 1}$, avec une substitution Gln $\rightarrow$ Glu (BPII). Le peptide 42 correspond exactement au fragment 174-181 de la caséine $\alpha_{s 2}$ (BPIII). Ces trois peptides étaient très amers en solution à $0,1 \%$. Le peptide 42 a également été isolé par Sparrer et Belitz (1975) après hydrolyse de la caséine par la trypsine. 
Tableau XIX. Peptides amers provenant de la dégradation des caséines mais dont la séquence ne correspond à aucun fragment des caséines $\alpha_{\mathrm{s} 1}$ et $\beta$.

Bitter peptides occuring from casein degradation but with sequences unknown in $\alpha_{s 1}$ and $\beta$ caseins.

\begin{tabular}{|c|c|c|c|}
\hline$N^{o}$ & Séquence & $\begin{array}{l}\text { Obtenu par } \\
\text { action de }\end{array}$ & Identification \\
\hline 36 & Arg-Gly-Pro-Pro-Phe*-lle-Val C-terminale de la caséine $\beta$ & Protéase $B$ subtilis & $\begin{array}{c}\text { 202-209 } \beta, 1 \text { inversion, } \\
1 \text { délétion }\end{array}$ \\
\hline 37 & Val-Tyr-Pro-Phe-Pro-Pro-Gly-Ile-Asn-His (BPIC) & Protéase $B$ subtilis & $59-68 \beta, 2$ inversions \\
\hline 38 & Val-Tyr-Pro-Phe-Pro-Pro-Gly & Synthèse & $59-65 \beta, 1$ inversion \\
\hline 39 & Cyclo (Leu-Trp-Leu-Trp) & Protéase $B$ subtilis & $\begin{array}{l}\text { C-terminal } \alpha_{s 1} \text { cyclisé } \\
\text { x2 }\end{array}$ \\
\hline 40 & Gly-Pro-Phe-Pro-Val-Ile & Trypsine & $203-208 \beta$, Ile $\rightarrow$ Val \\
\hline 41 & Phe-Phe-Val-Ala-Pro-Phe-Pro-Glu-Val-Phe-Gly-Lys & Trypsine & 23-34 $\alpha$ s1, Gln $\rightarrow$ Glu \\
\hline 42 & Phe-Ala-Leu-Pro-Gin-Tyr-Leu-Lys & Trypsine & $174-181 \alpha_{s 2}$ \\
\hline 43 & Val-Glu-Val-Phe-Ala-Pro-Pro-Phe & Chymotrypsine & $?$ \\
\hline 44 & Ala-Pro-Phe-Pro-Glu-Val-Phe & Cheddar & $26-33 \alpha_{s 1}$, Gin $\rightarrow$ Glu \\
\hline
\end{tabular}

Un autre hydrolysat trypsique de caséine a permis à Hill et Van Leeuwen (1974) d'isoler trois peptides amers. Ce sont tous des fragments de la caséine $\alpha_{s 1}(4,6,12)$.

Belitz et Sparrer (1971) ont obtenu deux peptides amers à partir d'un hydrolysat de caséine par la chymotrypsine. Le peptide 11 correspond au fragment 145-150 de la caséine $\alpha_{s 1}$. Par action de la thermolysine, il est dégradé en deux peptides $(10,13)$ également très amers. Le peptide 43 ne correspond pas à une séquence des caséines.

Pélissier et al (1974) ont étudié 11 peptides amers dont 8 proviennent de la caséine $\alpha_{s 1}$.

Parmi ces peptides, cinq avaient été obtenus lors de la détermination de la séquence des caséines $\alpha_{s 1}$ et $\beta(4,7,12$, pour $\alpha_{s 1}$ et 22,35 pour $\beta$ ) (Mercier et al, 1971 ; Ribadeau-Dumas et al, 1972). Les six autres peptides $\left(3,5,8,9,14\right.$ pour $\alpha_{s 1}$ et 26 pour $\beta$ ) ont été isolés d'hydrolysats des caséines $\alpha_{s 1}$ et $\beta$ par la présure. Le peptide 35 a été identifié à nouveau par Hashimoto et al (1980). Ce peptide a alors été synthé- tisé et son amertume comparée à celle du peptide naturel.

D'autres peptides amers provenant de la dégradation de la caséine $\beta$ ont été isolés. C'est le cas du peptide 18 isolé par Clegg et al (1974) après action de la papaine. Monnet et al (1986) ont étudié l'action de la protéase de paroi de L lactis NCDO 763 sur la caséine $\beta$. Cinq peptides ont alors pu être identifiés $(23,24,25,30,31)$. Les auteurs suggèrent que ces peptides, étant donné leur taille et leur hydrophobicité, pourraient être amers.

Quelques peptides synthétiques ont été utilisés pour déterminer leur saveur. Kanehisha (1984) a ainsi montré que le peptide 34 de la caséine $\beta$ était amer. Shinoda et al $(1985,1986 a, b)$ ont également étudié l'amertume des peptides 19, 20, 32 et de leurs fragments. Ils ont remarqué que le peptide 32 est composé de deux peptides amers (196-201 et 202-209). Ils ont également vérifié que la séquence était importante dans le mécanisme d'apparition de l'amertume en observant que le rétro- 
peptide 209-202 était moins amer que le peptide 202-209.

II faut noter que les identifications de peptides sont faites par comparaison aux séquences des caséines $\alpha_{s 1}$ et $\beta$ obtenues par Mercier et al (1971) et RibadeauDumas et al (1972). Toutefois, quelques erreurs ont été mises en évidence dans les années 1980 grâce au séquençage nucléotidique. Ainsi, dans la caséine $\alpha_{\mathrm{s} 1}$, la position 30 est occupée par un résidu Glu et non une GIn (Nagao et al, 1984). On peut donc penser que les peptides 4 et 41 sont les mêmes. Dans la caséine $\beta$, la position 175 est occupée par Gln et non Glu, tandis qu'en position 194 Gin est en fait Glu (Ribadeau-Dumas, non publié). Cette observation concerne les peptides 23 et 27 à 31 .

\section{Identification de peptides amers dans les fromages}

Certains peptides ont été isolés directement de fromages. Ainsi, des études sur le cheddar (Hodges et al, 1972) ont mené à l'identification des peptides $1,2,44$. Ce sont tous des peptides issus de la caséine $\alpha_{\text {s1 }}$, à une substitution près pour le peptide 44 (voir remarque ci-dessus).

Hamilton et al (1974) ont également isolé du cheddar un peptide de la caséine $\beta$ (17).

Le peptide 15 a été mis en évidence par Guigoz et Solms (1974) dans un fromage suisse de montagne et correspond au C-terminal de la caséine $\alpha_{51}$.

Visser et al (1983) ont extrait d'un Gouda trois peptides amers de la caséine $\beta$. Le peptide 29 correspond au fragment 193209. Le peptide 21 est très minoritaire mais amer toutefois. Le dernier peptide correspondrait au fragment 193-207 (27) ou 193-208 (28). L'incertitude subsiste quant à son extrémité C-terminale.

Récemment, Mojarro de Guerra (1989) et Mojarro de Guerra et al (1991) ont isolé sept peptides du fromage "Vacherin Mont d'or . Le peptide 33 correspond à la séquence $199-202$ de la caséine $\beta$. Les six autres peptides (Leu-Pro, Val-Pro, PhePro, Lys-Pro, Arg-Pro, et Tyr-Pro) sont des dipeptides présents dans les différentes caséines. L'hydrophobicité moyenne de ces peptides laissait penser que tous les dipeptides étaient amers. Cela a été vérifié sensoriellement et des flaveurs complémentaires ont été trouvées : " anesthésique " pour Lys-Pro, astringent pour Phe-Pro, " assaisonné " pour Val-Pro, "moules" pour Leu-Pro. La fraction extraite du fromage avait globalement un goût de bouilIon, était salée et amère.

Enfin, Roudot-Algaron et al (1993) ont isolé, de la fraction hydrosoluble du comté, cinq dicétopipérazines. Parmi ces molécules Cyclo (Pro-Val), Cyclo (Pro-Leu), et Cyclo (Pro-Phe) étaient très amers.

\section{Les autres peptides sapides du fromage}

Nous pouvons remarquer que l'amertume a été largement étudiée dans les hydrolysats de caséines.

Pourtant, une fraction astringente a été mise en évidence par Harwalkar et Elliott (1971), Harwalkar (1972) et Harwalkar et al $(1989,1993)$. Le mot astringent provient du latin " ad stingere " (lier) mais l'astringence est une sensation tactile constituant en général un défaut. Elle est souvent responsable d'une sensation de sécheresse, de reserrement des papilles gustatives. C'est un défaut fréquemment décrit, dans les laits stérilisés, comme crayeux, poudreux, rêche. Harwalkar et Elliott (1971) ont observé ce défaut dans les fractions amères extraites du cheddar. Harwalkar (1972) a partiellement caractérisé cette fraction. Soluble à $\mathrm{pH}$ acide et alcalin, elle peut être précipitée à $\mathrm{pH}$ neutre. Elle n'est astringente qu'à $\mathrm{pH}$ acide ou neutre. Le spectre de cette fraction est typique d'une solution protéique. Son point isoélectrique est voisin de 6,5 et sa vitesse de sédimentation $\left(S_{20}\right.$ w) est de 1,25 . Elle ne contient que très peu d'acides aminés libres, mais 
après hydrolyse, la proline et autres acides aminés hydrophobes sont prédominants. L'électrophorèse en présence d'urée, donne plusieurs bandes suggérant une fraction complexe contenant des peptides dont la masse moléculaire a été estimée entre 9 et $12 \mathrm{kDa}$ par filtration sur gel. Cette fraction contient de faibles quantités de $\mathrm{Ca}$, $\mathrm{Mg}$ et phosphore. Par comparaison avec l'astringence des produits phénoliques dans les fruits, les auteurs suggèrent l'intervention de la tyrosine dans ce phénomène. Harwalkar et al (1989) ont partiellement purifié les composés astringents d'un lait UHT et suggèrent qu'il s'agit de composés proches des caséines $\gamma$. Une étude plus récente (1993) leur a permis de confirmer ces résultats. Lemieux et Simard (1994) ont fait une synthèse sur l'astringence dans les produits laitiers.

On rencontre également dans la littérature des notes sucrées, brûlées, des flaveurs de bouillon, de noisette qui, d'après les auteurs, sont dues aux peptides (Law, 1981). Langler et al (1967) ont montré que les acides aminés (en particulier la proline) sont impliqués dans le goût sucré et que les peptides peuvent avoir une influence sur la flaveur. D'après Biede et Hammond (1979), le goût sucré du fromage suisse est dû à l'interaction des petits peptides avec des ions calcium et magnésium. Les peptides courts et moyens sont responsables des flaveurs brûlé, noisette, bouillon. Aston et Creamer (1986) ont extrait du cheddar une fraction hydrosoluble salée, amère, mais ayant également une flaveur de bouillon et de lait en poudre. Les auteurs suggèrent l'intervention des peptides dans la flaveur totale de cette fraction. RoudotAlgaron et al (1993) ont également extrait la fraction hydrosoluble d'un fromage de comté. Cette fraction était salée et umami. Son arôme, complexe, rappelait le bouillon, la noisette, le brûlé. Au cours de la caractérisation de ses principaux constituants, les auteurs ont identifié quelques dérivés d'acides aminés. Ils avaient un goût modé- rément amer, accompagné de la saveur salée pour $\mathrm{N}$-propionyl-Leu et $\mathrm{N}$-propionylPhe et de flaveurs fromagères pour $\mathrm{N}$-acétyl-Met et N-propionyl-Met.

De nombreux travaux ont montré l'importance de la fraction hydrosoluble non volatile du fromage sur le goût et l'intensité du goût. Les flaveurs de bouillon sont décrites de plus en plus souvent dans les hydrolysats de protéines. Elles sont généralement reliées à la présence d'acide glutamique. Roudot-Algaron et al (1994a) ont d'ailleurs isolé du comté des composés riches en acide glutamique. Le peptide $\gamma$-Glu-Phe était acide et salé tandis que le peptide $\gamma$-Glu-Tyr avait un goût complexe de bouillon, légèrement acide et salé.

À la recherche de peptides acides dans le comté, Roudot-Algaron et al (1994b) ont également isolé 13 phosphopeptides provenant, respectivement, des fragments 13 28 et 5-21 des caséines $\beta$ et $\alpha_{s 2}$. Ces peptides, particulièrement riches en acide glutamique et en sérine, n'ont toutefois pas été goûtés.

\section{CONCLUSION}

De nombreux travaux ont été effectués sur la relation protéolyse-développement de la flaveur. Le caractère organoleptique le plus souvent étudié a été l'apparition de l'amertume au cours de l'hydrolyse enzymatique des protéines. Cela se comprend facilement car l'amertume est souvent perçue comme un défaut. Pour maîtriser son développement, il fallait donc en connaître les mécanismes.

La fraction hydrosoluble du fromage contribue de façon importante à l'intensité globale de la flaveur des fromages (Mc Gugan et al, 1979 ; Aston et Creamer, 1986). Il a été montré par ultrafiltration et par perméation sur gel que la flaveur des fromages est concentrée dans une fraction contenant de petites molécules hydrosolubles $\left(M_{t}<1000\right)$ (Engels et Visser, 1994). Les petits peptides et les acides aminés 
libérés au cours de la protéolyse doivent y contribuer. Toutefois, hormis l'acide glutamique présent en grande quantité dans les caséines ( $19 \mathrm{~mol} \%$ ), la contribution directe des acides aminés présents dans cette fraction sapide doit être limitée (Olson, 1990). Cependant, les acides aminés libres sont susceptibles d'avoir un rôle de précurseurs d'arôme et d'être dégradés en composés aromatiques par des procédés enzymatiques ou non (Visser, 1993).

En ce qui concerne le rôle des peptides sapides non amers, il est de plus en plus probable que ceux-ci ne jouent pas un rôle prépondérant dans la saveur de la fraction hydrosoluble des fromages. En effet, un fractionnement de cet extrait (Salles et al, 1995 ; Le Bars et al, résultats non publiés) a montré que les fractions les plus aromatiques ne contenaient pas ou peu de peptides. De plus, les peptides présents sont en si faible quantité qu'il a été impossible jusqu'à présent de les identifier. Leurs faibles proportions dans la fraction étudiée et les seuils de détection obtenus sur des peptides synthétiques, nous amènent donc à penser que la flaveur de la fraction hydrosoluble du fromage ne revient pas de façon majoritaire aux peptides. Des résultats similaires ont été obtenus par Seitz (1990) sur un fromage de type EMC (enzyme modified cheese).

Toutefois, les peptides sapides existent, nous l'avons montré précédemment. Certains ont été isolés d'hydrolysats de protéines de poisson, de viande ou de soja. Ainsi, un octapeptide dit « délicieux ", a été isolé d'un extrait de viande (Yamasaki et Maekawa, 1978). II est riche en acide glutamique et en possède les propriétés organoleptiques (Tamura et al, 1989). Fujimaki et al (1973) ont isolé quelques di- et tripeptides umami obtenus par digestion enzymatique de protéines de poisson. En effet, après action de la pronase, ils ont obtenu une fraction ayant un goût complexe. Plusieurs étapes de séparation ont permis d'isoler une fraction acide ayant un goût umami très intense. Après avoir enlevé l'acide glutamique libre, cette fraction était encore umami. Une dizaine de peptides ont été identifiés. Ils étaient riches en acide glutamique et en acides aminés hydrophiles ; leurs caractéristiques gustatives et leurs seuils de détection étaient proches de celui du MSG (Noguchi et al, 1975a).

En conclusion, les saveurs présentes dans les hydrolysats de protéines sont directement liées à la composition et à la séquence des protéines. Ainsi, un hydrolysat de gélatine ne sera jamais amer, celuici étant riche en glycine, tandis qu'un hydrolysat de caséine contient de façon majoritaire des peptides hydrophobes et par conséquent amers. Certaines protéines de soja, de poisson, de viande semblent être de bons substrats pour obtenir des saveurs umami.

\section{RÉFÉRENCES}

Abe K, Yamashita H, Arai S, Kurihara Y (1992) Molecular cloning of Curculin, a novel taste-modifying protein with a sweet taste. Biochim Biophys Acta 1130, 232-234

Adler-Nissen J (1986) Enzymic hydrolysis of food proteins. Elsevier, London, 58

Anonyme (1987) Alitame: A new high intensity sweetener. Technical summary (Pfizer)

Anonyme (1990) L'amer et le sucré: l'espace des goûts est infini et continu. Pour Sci 150, 16-17

Arai S, Yamashita M, Noguchi M, Fujimaki M (1973) Tastes of $\mathrm{L}$-glutamyl oligopeptides in relation to their chromatographic properties. Agric Biol Chem 37. 151-156

Ardō Y, Gripon JC (1995) Characterization of proteolysis in some semi hard round eyed cheese varieties with different fat contents. J Dairy Res 62, 543-547

Aso K (1989) Enzymatic approach to the synthesis of a lysine containing sweet peptide, $\mathrm{N}$-acetyl-L-phenylalanine-L-lysine. Agric Biol Chem 53, 729-733

Aston JW, Creamer LK (1986) Contribution of the components of the water soluble fraction to the flavor of Cheddar cheese. NZJ Dairy Sci Technol 21, 229-248

Belitz HD, Sparrer D (1971) Isolierung eines bitteren peptids aus einem chymotryptischen caseinhydrolysat. Lebensm Wiss Technol 4, 131-132

Belitz HD, Wieser H (1976) Zur Konfigurationsabhängigkeit der süssen oder bitteren gesmacks von aminosaüren und peptiden. Z Lebensm Unters Forsch $160,251-253$

Berg CP (1953) Physiology of D-amino acids. Physiol Rev 33, 145-189 
Biede SL. Hammond EG (1979) Swiss cheese flavor: chemical analysis. J Dairy Sci 62, 227-237

Birch GG (1983) Chemical structure and gustatory perception. In: Research in food science and nutrition. Vol. IV. Food science and human welfare (Proc 6th Int Congr Food Science Technol) (JV McLoughlin, BM McKenna, eds). Boole Press, Dublin, 223-228

Birch GG, Kemp SE (1989) Apparent specific volumes and tastes of amino acids. Chem Senses 14, 249 258

Boesten WHJ, Dassen BHN, Kleinjans JCS, Vanagen B, Vanderwal S, Devries NK, Schoemaker HE, Meijer EM (1991) N-Formyl-carbamoyl-aspartame, a new aspartame-like sweetener. Synthesis and studies on stability and biological properties. $J$ Agric Food Chem 39, 154-158

Brouwer JN, Van der Wel $H$, Francke A, Henning $J$ (1968) Miraculine, the sweetness-inducing protein from Miracle fruit. Nature 220, 373-374

Clegg KM, Lim CL, Manson W (1974) The structure of a bitter peptide derived from casein digestion with papain. J Dairy Res 41, 283-287

Engels WJM, Visser S (1994) Isolation and comparative characterization of components that contribute to the flavour of different types of cheese. Neth Milk Dairy J 48, 127-140

Fujimaki M, Yamashita M, Ozkazawa Y, Arai S (1968) Diffusable bitter peptides in peptic hydrolysates of soybean protein. Agric Biol Chem 32, 794-795

Fujimaki M, Arai S, Yamashita M, Kato $H$, Noguchi M (1973) Taste peptide fractionation from a fish protein hydrolysate. Agric Biol Chem 37, 2891-2898

Guigoz Y, Solms J (1974) Isolation of a bitter tasting peptide from Alpkaese, a Swiss mountain cheese. Lebensm Wiss Technol 7, 356-357

Guigoz Y, Solms J (1976) Bitter peptides, occurence and structure. Chem Senses Flavor 2, 71-84

Haefeli RJ, Glaser D (1990) Taste response and thresholds obtained with the primary amino acids in human. Lebensm Wiss Technol 23, 523-527

Hamilton JS, Hill RD, Van Leeuwen H (1974) A bitter peptide from Cheddar cheese. Agric Biol Chem 38 , 375-379

Harwalkar VR, Elliott JA (1971) Isolation of bitter and astringent fractions from Cheddar cheese. J Dainy Sci 54, 8-11

Harwalkar VR (1972) Characterization of an astringent flavor fraction from cheddar cheese. J Dairy Scl 55 , 735-741

Harwalkar VR, Boutin-Muma B, Cholette H, Mc Kellar RC, Emmons DB (1989) Isolation and partial purification of astringent compounds from ultra high temperature sterilized milk. J Dairy Res $56,367-373$

Harwalkar VR, Cholette H, Mc Kellar RC, Emmons DB (1993) Relation between proteolysis and astringent fraction off-flavor in milk. J Dairy Sci 76, 2521-2527

Hashimoto A, Asyagi H, Izumiya N (1980) Synthetic identification of bitter heptapeptide in tryptic hydrolysate of casein. Bull Chem Soc Jpn 53, 2926-2928
Hettinger TP, Myers WE, Frank ME (1990) Role of olfaction in perception of non-traditional taste stimuli. Chem Senses 15, 755-760

Hill RD, Van Leeuwen H (1974) Bitter peptides from hydrolysed casein coprecipitate. Aust J Dairy Technol 29, 32-34

Hodges R, Kent SBH, Richardson BC (1972) The mass spectra of some permethylated acetylpeptides. Biochim Blophys Acta 257, 54-60

Huynh-Ba T, Philippossian G (1990) L-Ornithyltaurine, a new salty peptide. Comment. I Agric Food Chem 38,1993

Ikeda K (1909) On a new seasoning. J Tokyo Chem Soc 30, 820-836

Ishibashi $N$, Arita $Y$, Kanehisha $H$, Kouge $K$, Okai $H$, Fukui S (1987a) Bitterness of leucine containing peptides. Agric Biol Chem 51, 2389-2394

Ishibashi N, Sadamori K, Yamamoto $O$, Kanehisha $H_{\text {, }}$ Kouge K, Kikuchi E, Okai H, Fukui S (1987b) Bitterness of phenylalanine and tyrosine containing peptides. Agric Biol Chem 51, 3309-3313

Ishibashi N, Kubo T, Chino M, Fukui H, Shinoda I, Kikuchi $E$, Okai $H$, Fukui $S$ (1988a) Taste of proline containing peptides. Agric Biol Chem 52, 95-98

Ishibashi N, Kouge K, Shinoda I, Kanehisha H, Okai H (1988b) A mechanism for bitter taste sensibility in peptides. Agric Biol Chem 52, 819-827

Ishibashi N, Ono I, Kato K, Shigenaga T, Shinoda I, Okai $H$, Fukui S (1988c) Role of the hydrophobic amino acid residue in the bitterness of peptides. Agric Biol Chem 52, 91-94

Jamma C (1989) Le talent de nos papilles. Sci Avenir $512,49-52$

Kanehisha H (1984) Studies of bitter peptides from casein hydrolysate. IV) Synthesis and bitter taste of BPIc (Val-Tyr-Pro-Phe-Pro-Pro-Gly-lle-Asp-His) and its analogs and fragments. Bull Chem Soc Jpn $57,97-102$

Kato H, Rhue MR, Nishimura T (1989) Role of free amino acids and peptides in food taste. In: Flavor chemistry; trends and development, chap 13, (R Teranishi, RG Buttery, F Shahidi, eds). American Chemical Society, Washington, 159-174

Kemp SE, Beauchamp GK (1994) Flavor modification by sodium chloride and monosodium glutamate. J Food Sci 59, 682-686

King GA, Sweeny JG, lacobucci GA (1991) New highpotency L-aspartyl-3-bicycloalkyl-L-alanine methyl ester sweeteners. J Agric Food Chem 39, 52-56

Kinghorn AD, Soejarto DD (1989) Intensely sweet compounds of natural origin. Med Res Rev 9, 91-115

Kirimura J, Shimizu A, Kimizuka A, Ninomiya T, Katsuya $N$ (1969) The contribution of peptides and amino acids to the taste of foodstufís. J Agric Food Chem 17, 689-695

Kleeman A, Leuchtenberger W, Hoppe B, Tanner H, Hanau-Wolfgang DAG (1985) Amino acids. In: Ullemans encyclopedia of industrial chemistry. $\mathrm{VCH}$ Verlagsgesellschaft, Weinheim, 57-97 
Kohmura M, Nio N, Ariyoshi Y (1990a) Complete amino acid sequence of the sweet protein Monellin. Agric Biol Chem 54, 2219-2224

Kohmura M, Nio N, Ariyoshi Y (1990b) Solid-phase synthesis and crystallization of Monellin, an intensely sweet protein. Agric Biol Chem 54, 1521-1530

Kohmura M, Nio N, Ariyoshi Y (1992) Highly probable active site of the sweet protein Monellin. Biosci Biotechnol Biochem 56, 1937-1942

Kohmura M, Nio N, Ariyoshi Y (1994) Solid-phase synthesis and structure-taste relationships of analogs of the sweet protein monellin. Blosci Biotechnol Biochem $58,1522-1524$

Kouge K, Shinoda I, Ishibashi N, Okai H (1988) Relation between bitterness and the distance of bitter taste determinant sites in cyclic-dipeptides. Chem Express $3,171-174$

Laing DG, Prescott J, Bell GA, Gillmore R, James C. Best DJ, Allen S, Yoshida M. Yamazaki K (1993) A cross-cultural study of taste discrimination with Australians and Japanese. Chem Senses 18, 161-168

Langler JE, Libbey LM, Day EA (1967) Identification and evaluation of selected compounds in Swiss cheese flavor. J Agric Food Chem 15, 386-391

Law BA (1981) The formation of aroma and flavour compounds in fermented dairy products. Dairy Sci Abstr $43,143-154$

Lemieux L, Simard RE (1991) Bitter flavour in dairy products : I.A review of the factors likely to influence its development mainly in cheese manufacture. Lait 71, 599-636

Lemieux L, Simard RE (1992) Bitter flavour in dairy products. II. A review of bitter peptides from caseins: their formation, isolation and identification, structure masking and inhibition. Lait 72, 335-382

Lemieux I, Simard RE (1994) Astringency, a textural defect in dairy products. Lait 74, 217-240

Lowrie RJ, Lawrence RC, Pearce LE (1972) Cheddar cheese flavour : 3) The growth of lactic streptococci during cheesemaking and the effect on bitterness development. N Z J Dairy Sci Technol 7, 44-50

Maga JA (1983) Flavor potentiators. CRC Crit Rev Food Sci Nutr 18, 231-312

Mandal C, Shirley F, Anchin JM, Mandal C, Linthicum DS (1991) Monoclonal antibodies to sweet taste proteins. I. Analysis of antigenic epitopes on Thaumatin by competitive inhibition assays. Hybridoma 10 . 459-466

Matoba T, Hata T (1972) Relationship between bitterness of peptides and their chemical structures. Agric Biol Chem 36, 1423-1431

Matoba T, Hayashi R, Hata T (1970) Isolation of bitter peptides from tryptic hydrolysate of casein and their chemical structure. Agric Biol Chem 34, 1235-1243

Mazur RH, Schlatter JM, Goldkamp AH (1969) Structure taste relationships of some dipeptides. J Am Chem Soc 91, 2684-2691

Mc Leod P (1990) Évaluation sensorielle : manuel méthodologique. Tec \& Doc, Lavoisier, Paris, 9

Mc Gugan WA, Emmons DB, Larmond E (1979) Influence of volatile and non-volatile fraction on inten- sity of Cheddar cheese flavor. J Dairy Sci 62,398 403

Mc Pherson A, Weickmann J (1990) X-ray analysis of new crystal forms of the sweet protein Thaumatin. J Biomol Struct Dyn 7, 1053-1060

Meister A (1965) Biochemistry of the amino acids. Academic Press, New York

Mercier JC, Grosclaude F, Ribadeau-Dumas B (1971) Structure primaire de la caséine $\alpha_{s 1}$ bovine : séquence complète. Eur J Biochem 23, 41-51

Minamiura N. Matsumara Y, Fukumoto J, Yamamoto T (1972a) Bitter peptides in cow milk casein digests with bacterial proteinases. I) Isolation and determination of amino acids sequence of a bitter peptide. Agric Biol Chem 36, 588-595

Minamiura N, Matsumura Y, Yamamoto T (1972b) Bitter peptides in the casein digests with bacterial proteinase: 2) Abitter peptide consisting of tryptophan and leucine. J Biochem 72, 841-848

Mojarro de Guerra SH (1989) Isolation of low-molecular weight taste peptides from Vacherin Mont d'Or cheese. Diss. ETH No8913, Zurich

Mojarro de Guerra SH, Amado R, Arrigoni E Solms J (1991) Isolation of low-molecular-weight taste peptides from Vacherin Mont d'Or cheese. I Food Sci $56,943-947$

Monnet V, Le Bars D, Gripon JC (1986) Specificity of a cell wall proteinase from Streptococcus lactis NCDO 763 towards $\beta$ casein. FEMS Microbiol Lett $36,127-131$

Morris JA, Cagnan RM (1972) Purification of Monellin the sweet principle of Dioxoreophyllum cumminsi. Biochim Biophys Acta 261, 114-122

Murzin AG (1993) Sweet-tasting protein Monellin is related to the cystatin family of thiol proteinase inhibitors. J Mol Biol 230, 689-694

Nagai T, Nishimura K, Suzuki H, Banba $Y$, Sasaki $H$, Kiuchi K (1994) Isolation and characterization of a Bacillus subtilis strain producing Natto with strong umami-taste and high viscosity. I Jap Soc Food Sci Technol 41, 123-128

Nagao M, Maki M, Sasaki $R_{i}$ Shiba $H$ (1984) Isolation and sequence analysis of bovine $\alpha s 1$ casein. Agric Biol Chem 48, 1663-1667

Ney KH (1971) Prediction of bitterness of peptides from their amino-acid composition. $Z$ Lebensm Unters Forsch 147, 64-68

Nishimura T, Kato $H$ (1988) Taste of free amino acids and peptides. Food Rev Int 4, 175-194

Noguchi M, Arai S, Yamashita M, Kato H, Fujimaki M (1975a) Isolation and identification of acidic oligopeptides occuring in a flavor potentiating fraction from a fish protein hydrolysate. J Agric Food Chem 23, 49-53

Noguchi M, Yamashita M, Arai S, Fujimaki M (1975b) On the bitter-masking activity of a glutamic acid-rich oligopeptide fraction. J Food Sci 40, 367-369

Nosho $Y$, Seki T, Kondo M, Ohfuji T, Tamura M, Okai H (1990) Molecular design of inverted-aspartame-type sweeteners. J Agric Food Chem 38, 1368-1373

Ohashi S. Ura F. Takeuchi M, lida H, Sakaue K, Ochi T, Ukai S, Hiramatsu K (1991) Interaction of Thaumatin 
with carrageenans. 4. Method for prevention of reduction of sweetness intensity of Thaumatin in interaction with carrageenan at $\mathrm{pH}-4$. Food Hydrocolloids 5, 375-391

Ohyama S, Ishibashi N. Tamura M. Nishizaki H, Okai H (1988) Synthesis of bitter peptides composed of aspartic acid and glutamic acid. Agric Biol Chem 52 , $871-872$

Okai H (1977) Relationship between bitterness and chemical structure in synthetic peptides. In : Peptide chemistry 1976 (T Nakajima, ed). Protein Research Foundation, Osaka, Japon, 139-142

Olson NF (1990) The impact of lactic acid bacteria on cheese flavor. FEMS Microbiol Rev 87, 131-148

Ota M. Nio N. Ariyoshi Y (1993) Enzymatic synthesis and chemical properties of sweet aminomalonyl (Ama) dipeptide esters (R)-Ama- (S)-Phe-OMe and (A)-Ama- (S)-Phe-OEt. Biosci Biotechnol Biochem $57,808-813$

Otagiri K, Nosho Y, Shinoda I, Fukui $\mathrm{H}$, Okai H (1985) Studies on a model of bitter peptides including arginine, proline and phenylalanine residues: 1) Bitter taste of di- and tri-peptides, and bitterness increase of the model peptides by extension of the peptide chain. Agric Biol Chem 49, 1019-1026

Pélissier JP, Mercier JC, Ribadeau-Dumas B (1974) Étude de la protéolyse des caséines $\alpha_{61}$ et $\beta$ bovines par la présure. Spécificité d'action. Peptides amers libèrés. Ann Biol Anim Biochim Biophys 14, 343-362

Penamubia L, Kim R, Giovannoni J, Kim SH, Fischer RL (1992) Production of the sweet protein Monellin in transgenic plants. Biotechnology 10, 561-564

Rhodes J, Titherley A, Norman JA, Wood R, Lord DW (1991) A survey of the monosodium glutamate content of foods and an estimation of the dietary intake of monosodium glutamate. Food Addit Contam 8, 265-274

Ribadeau-Dumas B, Brignon G, Grosclaude F, Mercier $J C$ (1972) Structure primaire de la caséine $\beta$ bovine : séquence complète. Eur J Biochem 25, 505-514

Roudot-Algaron F, Le Bars D, Einhorn J, Adda J, Gripon JC (1993) Flavor constituents of aqueous fraction extracted from Comté cheese by liquid carbon dioxide. J Food Sci 58, 1005-1009

Roudot-Algaron F, Kerhoas L, Le Bars D, Einhorn J, Gripon JC (1994a) Isolation of gamma-glutamyl peptides from Comté cheese. J Dairy Sci 77, 11611166

Roudot-Algaron F, Le Bars D, Kerhoas L, Einhorn J. Gripon JC (1994b) Phosphopeptides from Comté cheese. J Food Sci 59, 544-547

Salles C, Septier C, Roudot-Algaron F, Guillot A, Etiévant $P(1995)$ Sensory and chemical analysis of fractions obtained by gel permeation of water soluble Comté cheese extracts. J Agric Food Chem 43, 1659-1668

Sardesai VM, Waldshan TH (1991) Natural and synthetic intense sweeteners. J Nutr Biochem 2, 236-244

Schiffman SS, Dackis CH (1975) Taste of nutrients: amino acids, vitamins and fatty acids. Percept Psychophys 17, 140-146.
Schiffman SS, Engelhard HH (1976) Taste of dipeptides. Physiol Behav 17, 523-535

Schiffman SS, Sennewald K, Gagnon J (1981) Comparison of taste qualities and thresholds of $D$ - and L-amino acids. Physiol Behav 27, 51-59

Seitz EW (1990) Microbial and enzyme induced flavors in dairy foods. J Dairy Sci 73, 3664-3691

Seki T, Tamura M, Nosho Y, Ohfuji T, Okai H (1990) Studies on flavored peptides. 9. Delta-acetyl-L-ornithyl-beta-alanine methyl ester hydrochloride, an intermolecule type sweetener. Agric Biol Chem 54 , $1811-1818$

Shallenberger RS, Acree TE (1967) Molecular theory of sweet taste. Nature 216, 480-482

Shallenberger RS, Acree TE (1971) Chemical structure of compounds and their sweet and bitter taste. In: Handbook of sensory physiology (LM Beidler, ed). Springer-Verlag, Berlin, 221-277

Shepherd R (1988) Sensory influences on salt, sugar and fat intake. Nutr Res Rev 1, 125-144

Shiba T, Nunami K (1974) Structure of a bitter peptide in casein hydrolysate by bacterial proteinase. Tetrahedron Lett 6, 509-512

Shinoda I, Okai H (1985) Sweetness and bitterness contributions of structural units of Aspartame and some analogues. J Agric Food Chem 33, 792-795

Shinoda I, Fushimi A, Kato H, Okai H, Fukui S (1985) Bitter taste of synthetic C-terminal tetradecapeptide of bovine beta casein Pro-Val-Leu-Gly-Pro-Val-ArgGly-Pro-Phe-Pro-lle-lle-Val and its related peptides. Agric Biol Chem 49, 2587-2596

Shinoda I, Tada M, Okai H, Fukui S (1986a) Bitter taste of Pro-Phe-Pro-Gly-Pro-lle-Pro corresponding to the partial sequence (positions 61-67) of bovine $\beta$ casein, and related peptides. Agric Biol Chem 50 , 1247-1254

Shinoda I, Nosho Y, Otagiri K, Okai H, Fukui S (1986b) Bitterness of diastereosomers of a hexapeptide (Arg-Arg-Pro-Pro-Phe-Phe) containing D-phenylalanine in place of L-phenylalanine. Agric Biol Chem $50,1785-1790$

Shinoda I, Nosho $\mathrm{Y}$, Kouge $\mathrm{K}$, Ishibashi N, Okai H, Tatsumi K, Kikuchi E (1987) Variation in bitterness potency when introducing Gly-Gly residue into bitter peptides. Agric Biol Chem 51, 2103-2110

Siemon IZ, Kolasa T, Paradowski A (1979) On the taste of stereoisomeric cyclic dipeptides containing a proline residue. Chem Senses Flavor 4, 127-133

Solms $J$ (1969) The taste of amino acids, peptides and proteins. J Agric Food Chem 17, 686-688

Solms J, Vutaz L, Egli RH (1965) The taste of L-and Damino acids. Experientia 21, 692-694

Sparrer D, Belitz HD (1975) Bittere peptide aus Casein nach hydrolyse wit $\alpha$-Chymotrypsin und Trypsin. Z Lebensm Unters Forsch 157, 197-204

Stanley DW (1981) Non bitter protein hydrolysates. Can Inst Food Sci Technol J 14, 49-52

Stephen AG, Powls R, Beynon RJ (1991) The relationship between thaumatin, a sweet protein, and thaumatopain, a cysteine protease, from the arils of 
Thaumatococcus danielli. Biochem Soc Trans 19 , 2975

Stevens JC, Cain WS (1993) Changes in taste and flavor in aging. CRC Crit Rev Food Sci Nutr 33, 27-37

Tada M, Shinoda I, Okai H (1984) L-ornithyl-taurine, a new salty peptide. J Agric Food Chem 32, 992-996

Tamura M, Okai H (1990) Rebuttal on L-ornithyltaurine, a new salty peptide. J Agric Food Chem 38, 1994

Tamura M, Nakatsuka T, Tada M, Kawasaki Y, Kikuchi $\mathrm{E}$, Okai $\mathrm{H}(1989)$ The relationship between taste and primary structure of * Delicious Peptide " (Lys-GlyAsp-Glu-Glu-Ser-Leu-Ala) from beef soup. Agric Biol Chem 53, 319-325

Tamura M, Mori N, Miyoshi T, Koyama S, Kohri H, Okai $H(1990)$ Practical debittering using model peptides and related compounds. Agric Biol Chem 54, 41-51

Teeuwen $H$ (1991) Outlook for high intensity sweeteners. Int Food Ingredient 4, 4-9

Tsoubeli MN, Labuza TP (1992) Influence of dairy proteins on aspartame stability in the $\mathrm{pH} \mathrm{6-7}$ range. $J$ Food Sci 57, 361-365

Ugawa T, Konosu S, Kurihara K (1992) Enhancing effects of $\mathrm{NaCl}$ and $\mathrm{Na}$ phosphate on human gustatory responses to amino acids. Chem Senses 17, 811815

Van der Wel H, Loeve K (1972) Isolation and characterization of thaumatin I and II, the sweet-tasting proteins from Thaumatococcus danielli Benth. Eur $J$ Biochem 31, 221-225

Van der Wel H, Ledeboer AM (1989) The thaumatins. In: The biochemistry of plants. vol 15 (AMarcus, ed). Nederlandse Unilever Bedrijven BV, Rotterdam, Pays-Bas, 379-391

Van der Wel H, Larson G, Hladik A, Hellekant G, Glaser D (1989) Isolation and characterization of pentadin, the sweet principle of Pentidiplandra brazzeana Baillon. Chem Senses 14, 75-79

Vincent C, Delest P (1990) Food additives and flavours. It is always more natural with biotechnology. Biofutur 5, 69-79

Visser FMW (1977) Contribution of enzymes from rennet, starter bacteria and milk to proteolysis and flavour development in Gouda cheese: 2) Development of bitterness and cheese flavour. Neth Milk Dairy J 31, 188-209
Visser S (1993) Symposium: proteolytic enzymes and cheese ripening - Proteolytic enzymes and their relation to cheese ripening and flavor. An overview. J Dairy Sci 76, 329-350

Visser S, Slangen KJ, Hup G, Stadhouders J (1983) Bitter flavour in cheese. 3) Comparative gel chromatographic analysis of hydrophobic peptide fraction from twelve Gouda type cheese and identification of bitter peptides isolated from a cheese made with Streptococcus cremoris strain HP. Neth Milk Dairy J 37, 181-192

Wieser H, Belitz HD (1975) Bitter peptides isolated from corn protein zein by hydrolysis with pepsin. ZLebensm Unters Forsch 159, 329-336

Wieser H, Jugel H, Belitz HD (1977) Zusammenhänge zwischen struktur und Sübgesmack bei Aminosäuren. Z Lebensm Unters Forsch 164, 277-282

Witty M (1990) Thaumatin II: A palatability protein. Trends Biotechnol 8, 113-116

Xiaozhu L, Maeda S, Zhong H, Aiuchi T, Nakaya K, Kurihara $Y$ (1993) Purification, complete amino acid sequence and structural characterization of the heat stable sweet protein Mabinlin II. Eur J Biochem 211. 281-287

Yamaguchi S (1991) Basic properties of umami and effects on human. Physiol Behav 49, 833-841

Yamasaki Y, Maekawa K (1978) A peptide with delicious taste. Agric Biol Chem 42, 1761-1765

Yamasaki Y, Maekawa K (1980) Synthesis of a peptide with delicious taste. Agric Biol Chem 44, 93-97

Yamashita H, Theerasilp S, Aiuchi T, Nakaya K, Nakamura $Y$, Kurihara $Y(1990)$ Purification and complete amino acid sequence of a new type of sweet protein with taste-modifying activity, Curculin. J Biol Chem 265, 15770-15775

Yeom HW, Kim KS, Rhee JS (1994) Soy protein hydrolysate debittering by lysine-acetylation. J Food Sci $59,1123-1126$

Yokomukai Y, Cowart BJ, Beauchamp GK (1993) Individual differences in sensitivity to bitter-tasting substances. Chem Senses 18, 669-681

Yoshida M, Saito S (1969) Multidimensional scaling of the taste of amino acids. Jap Psychol Res 11, 149-166

Zeng GZ, Chen JT, He HZ, Wang ZQ, Yan JS (1991) In the pursuit of a better sweetener. J Agric Food Chem $39,782-785$ 